\title{
A Recent Study of Seasonal and Interannual Climate Variability over the Eastern Mediterranean Region
}

\author{
Yehia Hafez \\ Department of Meteorology, King Abdulaziz University, Jeddah, KSA \\ Email: ysalam@kau.edu.sa
}

How to cite this paper: Hafez, Y. (2018) A Recent Study of Seasonal and Interannual Climate Variability over the Eastern Mediterranean Region. Journal of Geoscience and Environment Protection, 6, 132-151. https://doi.org/10.4236/gep.2018.61009

Received: December 15, 2017

Accepted: January 28, 2018

Published: January 31, 2018

Copyright $\odot 2018$ by author and Scientific Research Publishing Inc. This work is licensed under the Creative Commons Attribution International License (CC BY 4.0).

http://creativecommons.org/licenses/by/4.0/

\section{(c) (i) Open Access}

\begin{abstract}
The present work aims to investigate seasonal and interannual climatic variability over the eastern Mediterranean (EM) region through the period (19492016). The monthly data of meteorological elements of temperature, pressure and precipitation for the EM region during the period (1949-2016) has used and analyzed. Moreover, the monthly NCEP/NCAR reanalysis data composites for these meteorological elements over the EM region have used. The seasonal and interannual variability of meteorological elements (surface air temperature, air temperature at $1000 \mathrm{hpa}$ level, $500 \mathrm{hpa}$ level, $500 \mathrm{hpa}$ geopotential height, mean sea level pressure and precipitation) over the EM region during that period is studied. The anomaly, time series and correlation coefficient techniques, methods used for the data analysis. The results revealed that the climate variability of the EM region varied dramatically from season to season and from year to year through the period of study (1949-2016). There is a seasonal positive trend of temperature at $1000 \mathrm{hpa}$ and $500 \mathrm{hpa}$ levels and Geopotential height of $500 \mathrm{hpa}$ level over the EM region. Meanwhile, it found a seasonal negative trend of mean sea level pressure and precipitation rate. For the interannual climatic variable over the EM region, it noticed that there was a positive trend of annual air temperature at the levels of $1000 \mathrm{hpa}$ and 500 hpa. Meanwhile, there exists an annual negative trend anomaly of mean sea level pressure, 500 hpa geopotential height and precipitation rate over the EM region through the study period. It has become clear that the climate regime over the EM region is a complex regime.
\end{abstract}

\section{Keywords}

Seasonal, Interannual, Climatic Variability, Temperature, Pressure, Precipitation Rate, EM 


\section{Introduction}

The eastern Mediterranean (EM) is a region with a strongly seasonal climate due to the variability dominant of high and low pressure systems. This seasonal climatic variability is inclusive of both temperatures as well as precipitation. Moreover, much of the climate in the region is affected by mountainous terrain [1]. In addition, EM region has a specific position to create a climate with strongly seasonal precipitation over it. The EM climate is a unique climate due to the position of EM region. It lies between the subtropical region and extratropical region to the north. Its position includes the Mediterranean Sea [2]. In fact, the climate of the EM region is mostly temperate with warm to hot, dry summers, and mild, with relatively wet winters [3] [4] [5]. In the southern EM region, the northeastern part of Africa, an arid, hot desert climate prevails, where precipitation has small amounts [6]. However, the temperature and precipitation gradients across the region of EM are remarkable [7]. It found that precipitation patterns in the EM region do not only depend on the synoptic weather conditions, but also on the pronounced topography [8] and [9]. It is noticed that precipitation could increase in mountainous regions in the north east of EM region, and possibly in the Northern part of Africa; southern region of the EM owes to the northward expansion of the tropical rain belt [10] [11]. The EM region is likely to be greatly affected by climate change, associated with increases in the frequency and intensity of droughts and hot weather conditions [12]. In fact, the EM region suffered from an abnormally warm and dry winter season in 2006. It found that, there was a positive correlation coefficient between the geopotential height anomaly at 500 hpa over Europe and the increase of surface air temperature and mean sea level pressure mainly in the eastern Mediterranean [13] [14]. He found that there existed of a teleconnection between the global mean surface air temperature and precipitation over Europe including the eastern Mediterranean region. It is obvious that the climate of the EM region lies in the transition zone between the Mediterranean climate and the semi-arid/arid climate. A study of a 39-year period was to determine whether climate changes had taken place. It found that changes of atmospheric conditions during summer and the transitional seasons (mainly autumn) supported a warmer climate over the EM. This change is already statistically evident in surface air temperatures which had exhibited positive trends of $0.2^{\circ} \mathrm{C} /$ decade $-1^{\circ} \mathrm{C} /$ decade. The EM region is under climate change leading to warmer and drier conditions through the period of study [15]. Recently, it found that there was a relationship between geopotential height variability over Europe and existing extreme abnormal weather over the Eastern Mediterranean and Middle East during December 2013 [16]. For abrupt climatic variations in the EM, it is necessary to investigate the climatic variability over the EM for a long period. The aim of the present study is to investigate a recent study of the seasonal and interannual variability of the climatological parameters over the EM region through the period (1949-2016). 


\section{Data and Methodology}

The monthly data of NCEP/NCAR reanalysis composites for the meteorological parameters are used. The meteorological elements used in the present work are (air temperature in the surface, $1000 \mathrm{hpa}$ level, $500 \mathrm{hpa}$ level, $500 \mathrm{hpa}$ geopotential height, mean sea level pressure and precipitation rate). The domain of the present study is the eastern Mediterranean region of $\left(23^{\circ} \mathrm{N}-50^{\circ} \mathrm{N}\right)$ latitudes and $\left(20^{\circ} \mathrm{E}-46^{\circ} \mathrm{E}\right)$ longitudes. These data are gridded data with mish $(12 \times 12)$ grid points of the eastern Mediterranean region. Whereas, the NCEP/NCAR gridded for these meteorological data are with temporal interpolation of 2.5 degree latitude $\times 2.5$ degree longitude global grid $(144 \times 73)$. The period of this scientific work is the period (1949-2016). However, the long-term means for monthly values of the meteorological parameters has taken for the period (1981-2010). This data supported from the site of NOAA/OAR/ESRL PSD, Boulder, Colorado, USA and according to [17]. The method of research through this work is unique method. Where there is a combination of several techniques has used. The data sets analyzed using time series, anomaly methodology and linear correlation coefficient techniques. The correlation analysis follows the Pearson correlation method according to [18].

\section{Results}

\subsection{The Seasonal Climatic Variability over EM Region through the Period (1949-2016)}

For study of seasonal climatic variability over the EM region, the monthly data of NCEP/NCAR reanalysis data for the meteorological parameters (air temperature in the surface, $1000 \mathrm{hpa}$ level, $500 \mathrm{hpa}$ level, $500 \mathrm{hpa}$ geopotential height, mean sea level pressure and precipitation rate) are used. This monthly data analyzed for four seasons through the period (1949-2016). These four seasons are winter, spring, summer and autumn respectively, whereas, December, January and February are represented the winter season. March, April and May months represent the spring season. June, July and August months represent a summer season. Meanwhile, the months of September, October and November are the autumn season. For each season, the normal values of the meteorological elements "climatic mean values" are taken for the period (1981-2010). Anomaly and time series methods for the above-mentioned meteorological elements are used. The results revealed that:

1) It is clear that almost of the EM region has increased in surface air temperature in the winter season than its normal values through the period of study, whereas, the positive anomaly in temperature reached to its maximum value $\left(+0.7^{\circ} \mathrm{C}\right)$ over Turkey. See Figure 1(a). In spring season, it noticed that almost of the EM region has a negative anomaly in surface air temperature. This negative anomaly in temperature reached $\left(-0.3^{\circ} \mathrm{C}\right)$ over Syria, as shown in Figure 1(b). For the summer season, the entire EM region has a decrease of surface air 
NCEP/NCAR Reanalysis

Surface air (C) Composite Anomaly 1981-2010 climo

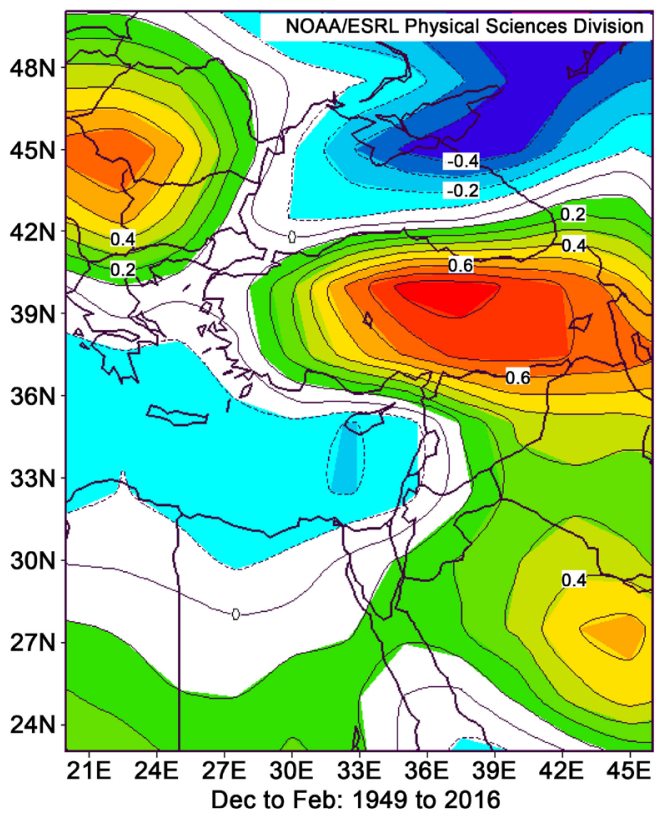

(a)

NCEP/NCAR Reanalysis

Surface air (C) Composite Anomaly 1981-2010 climo

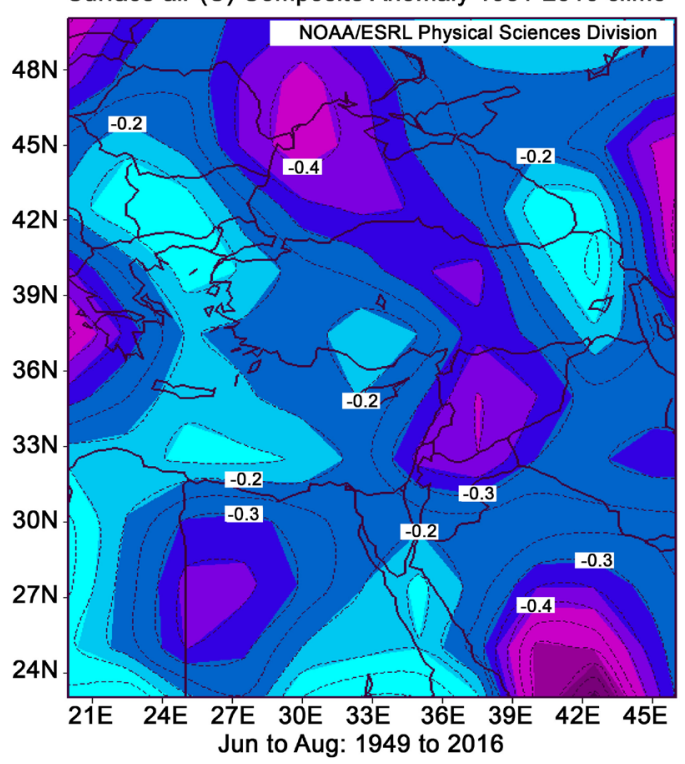

(c)
NCEP/NCAR Reanalysis

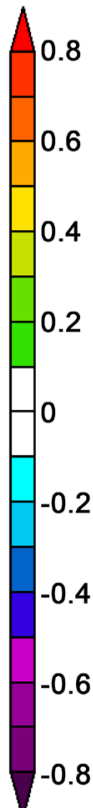

Surface air (C) Composite Anomaly 1981-2010 climo

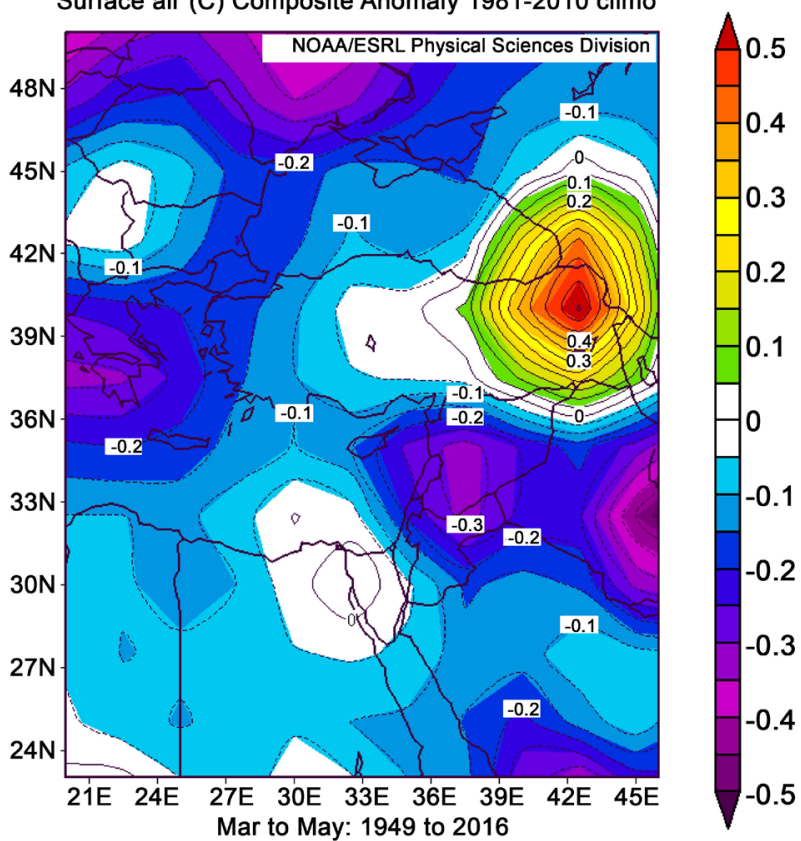

(b)

NCEP/NCAR Reanalysis

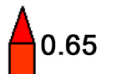

Surface air (C) Composite Anomaly 1981-2010 climo

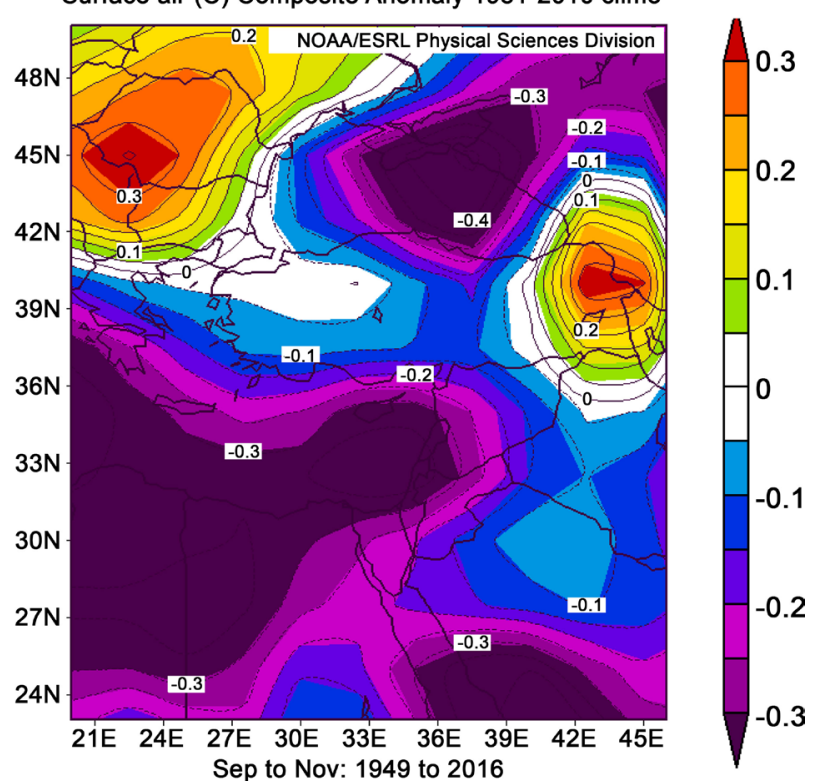

(d)

Figure 1. Seasonal distribution of surface air temperature anomaly over the Eastern Mediterranean region through the period (1949-2016). (a) For winter season, (b) For spring season, (c) For summer season, and (d) For autumn season.

temperature rather than its normal values. This decreasing reached to $\left(-0.4^{\circ} \mathrm{C}\right)$ from its normal value, as clear from Figure 1(c). In addition to that, for the autumn season the northeastern part of Africa and the Mediterranean Sea have an outstanding cooling of temperature. The surface air temperature of this season reached to $\left(-0.3^{\circ} \mathrm{C}\right)$ less than its seasonal climatic mean. As illustrated in Figure 
$1(\mathrm{~d})$.

2) For $500 \mathrm{hpa}$ level, temperature in winter season has a positive anomaly $\left(+0.15^{\circ} \mathrm{C}\right)$ over Libya and western part of Egypt and the northeastern part of the eastern Mediterranean region. In contradicting to that, there is a negative temperature anomaly over the northeastern part of the EM region $\left(-0.2^{\circ} \mathrm{C}\right)$. As shown in Figure 2(a). For spring season almost of the EM region has a negative anomaly of temperature reached to $\left(-0.35^{\circ} \mathrm{C}\right)$ as it is clear from Figure 2(b). In

NCEP/NCAR Reanalysis

500mb air (C) Composite Anomaly 1981-2010 climo

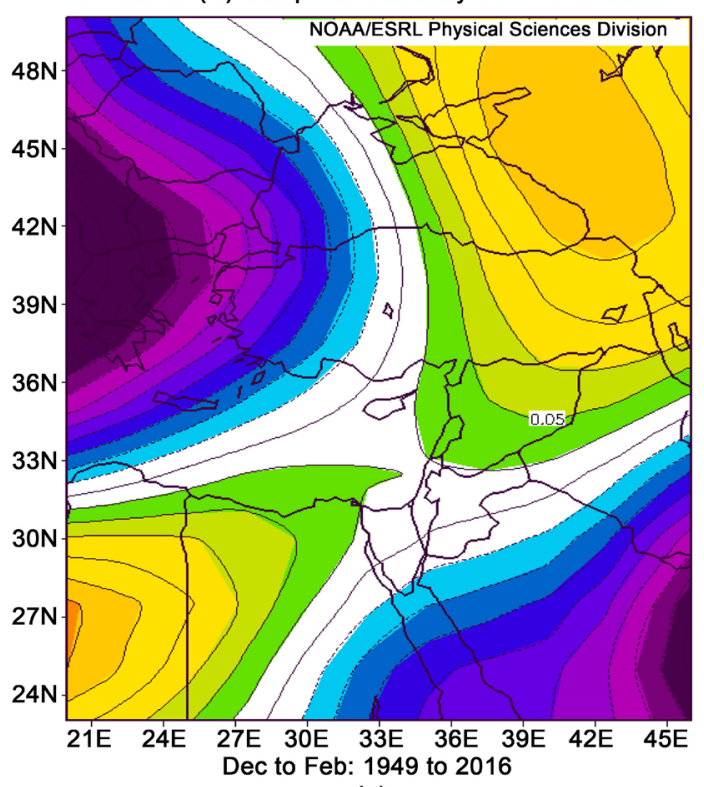

(a)

NCEP/NCAR Reanalysis

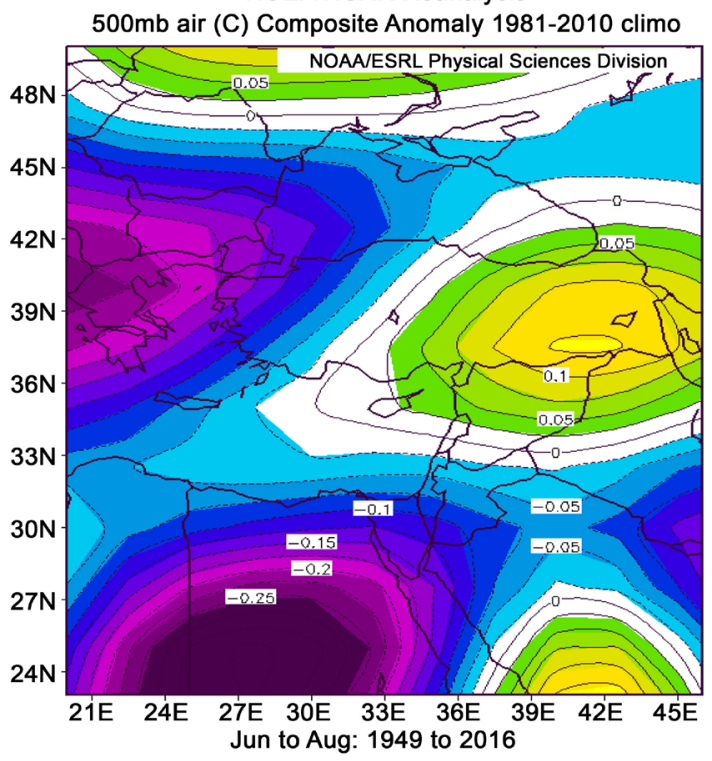

(c)
NCEP/NCAR Reanalysis
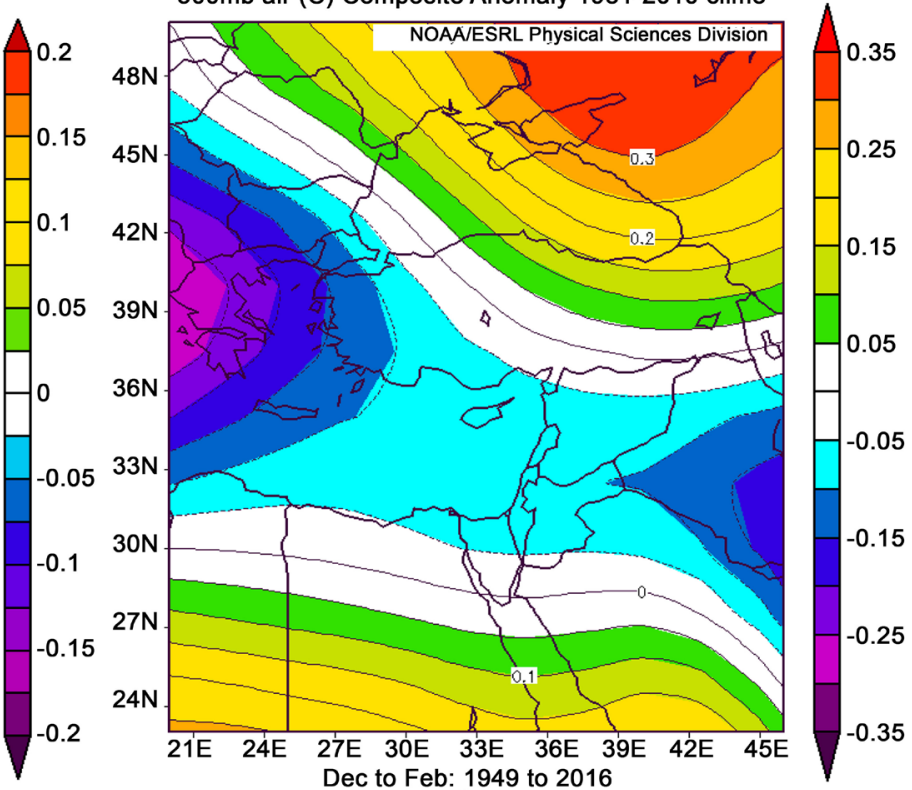

(b)

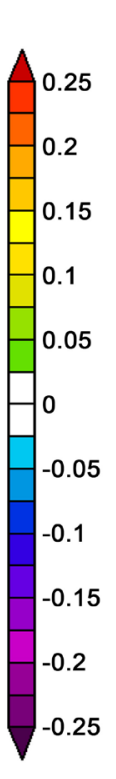

NCEP/NCAR Reanalysis

$500 \mathrm{mb}$ air (C) Composite Anomaly 1981-2010 climo

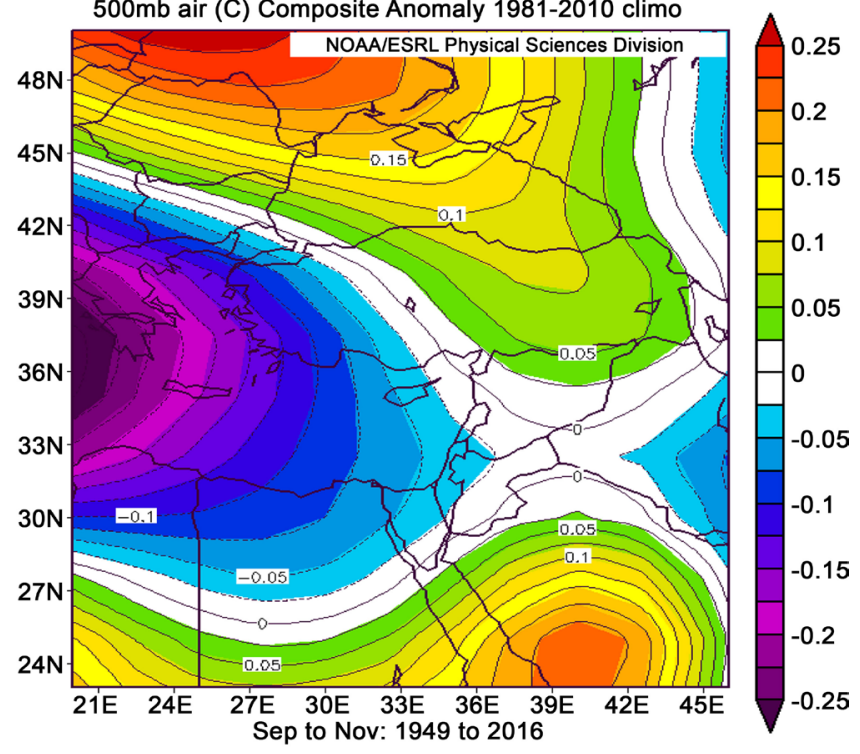

(d)

Figure 2. Seasonal distribution of air temperature anomaly at 500-hpa level over the Eastern Mediterranean region through the period (1949-2016). (a) For winter season, (b) For spring season, (c) For summer season, and (d) For autumn season. 
summer season the western part of the EM region has a negative anomaly of temperature $\left(-0.25^{\circ} \mathrm{C}\right)$ meanwhile the eastern part of the EM region has a positive temperature anomaly $\left(+0.15^{\circ} \mathrm{C}\right)$ at level 500 hpa. See Figure 2(c). The EM region has a negative temperature anomaly reached to $\left(-0.25^{\circ} \mathrm{C}\right)$ as illustrated in Figure 2(d).

3) Analysis of the mean sea level pressure over the entire EM region has a negative anomaly of temperature for all the four seasons. In winter season it is reached to $\left(-1.8^{\circ} \mathrm{C}\right)$ over Turkey. In spring season it is reached to $\left(-1.6^{\circ} \mathrm{C}\right)$ over the eastern part of Turkey. In summer and autumn seasons, it is found that $\left(-1.2^{\circ} \mathrm{C}\right)$ and $\left(-1.4^{\circ} \mathrm{C}\right)$ over eastern Turkey respectively during the period of study, as it is clear from Figures $3(\mathrm{a})-(\mathrm{d})$.

NCEP/NCAR Reanalysis

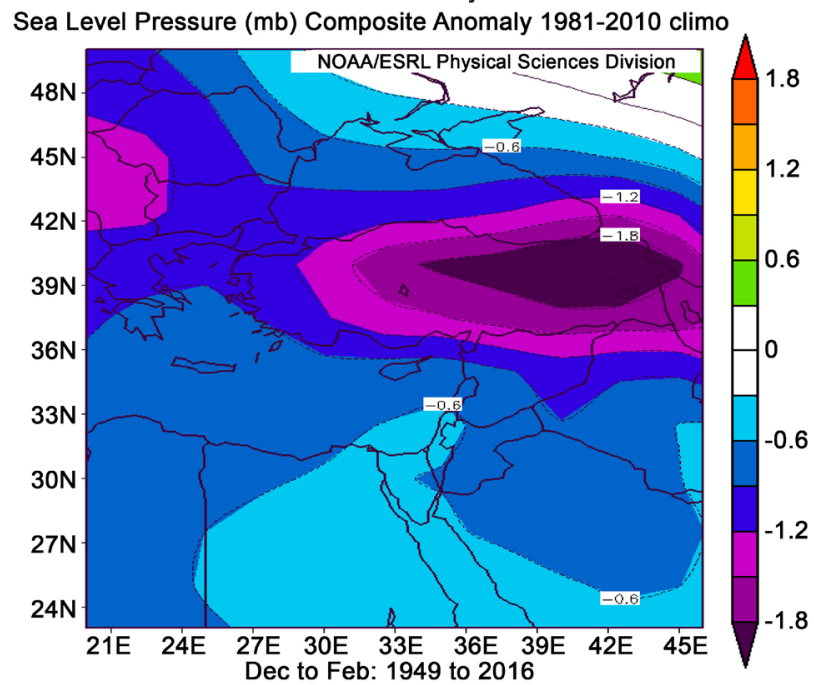

(a)

NCEP/NCAR Reanalysis

Sea Level Pressure (mb) Composite Anomaly 1981-2010 climo

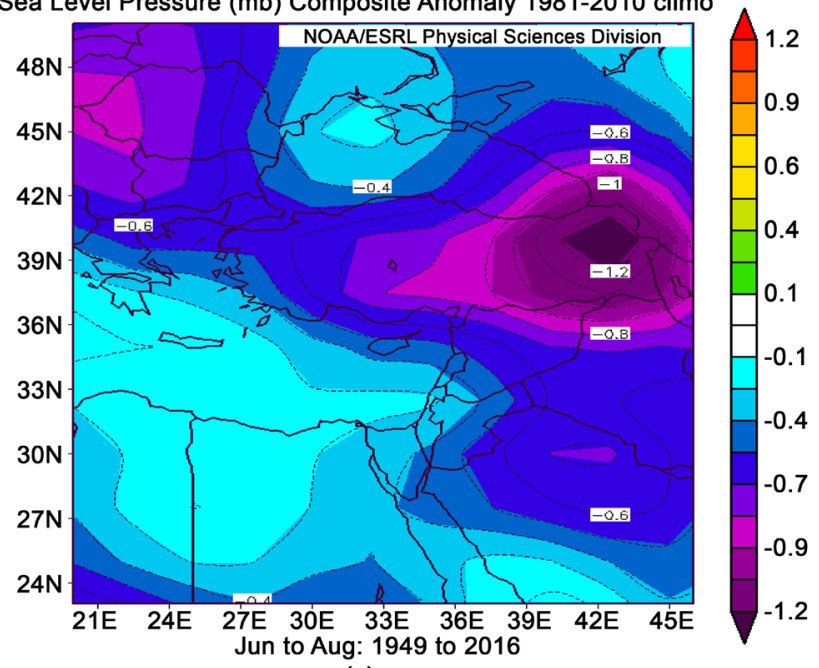

(c)

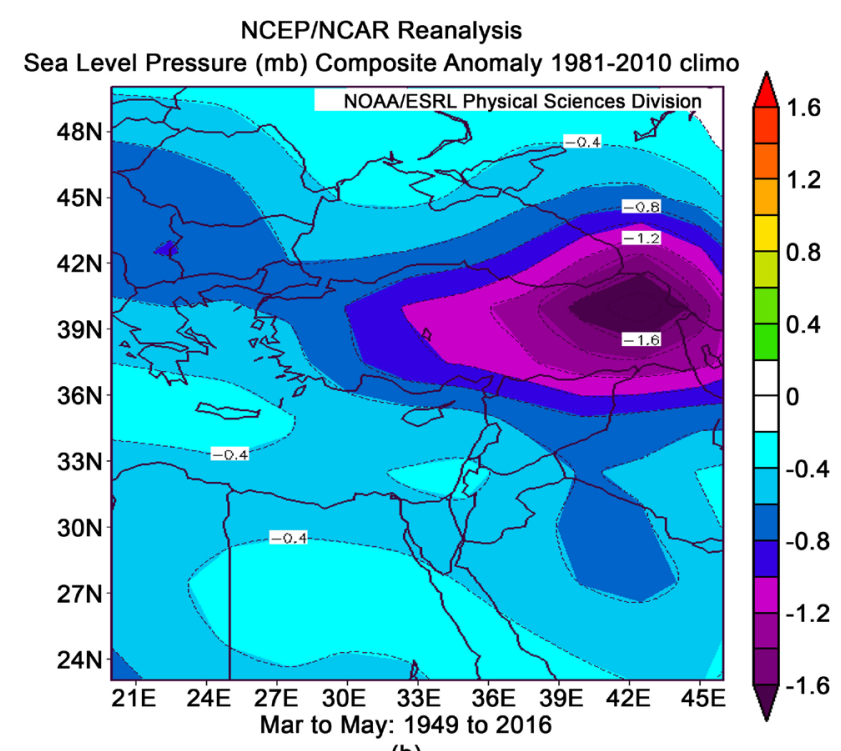

(b)

NCEP/NCAR Reanalysis

Sea Level Pressure (mb) Composite Anomaly 1981-2010 climo

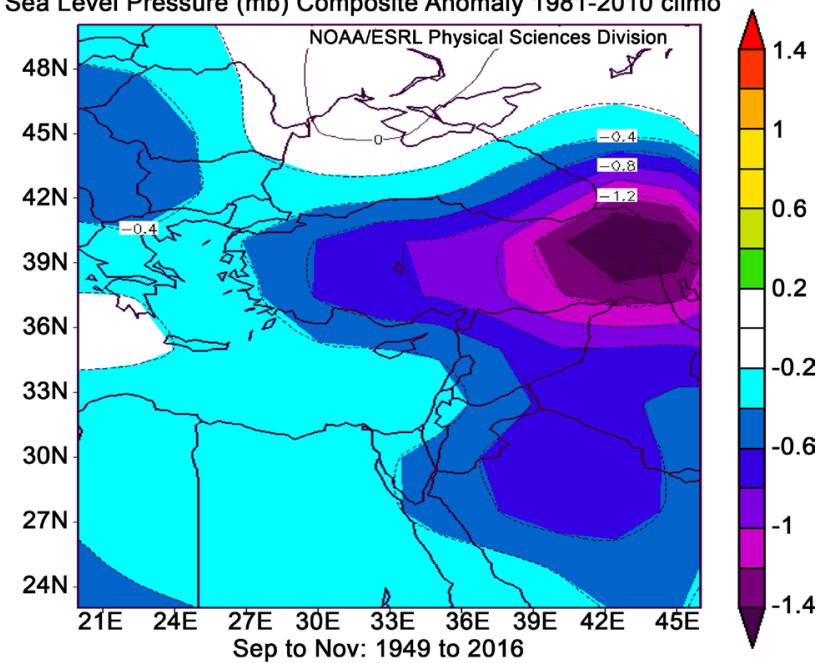

(d)

Figure 3. Seasonal distribution of the mean sea level pressure anomaly over the Eastern Mediterranean region through the period (1949-2016). (a) For winter season, (b) For spring season, (c) For summer season, and (d) For autumn season. 
4) Analysis of seasonal 500 hpa geopotential height anomaly during the period (1949-2016) shows that the EM region aloft has an outstanding negative anomaly of geopotential height for all seasons. It is reached to $(-11 \mathrm{~m})$ over Greece, $(-10 \mathrm{~m})$ over Syria, $(-10 \mathrm{~m})$ over the northern part of the EM region and $(-8 \mathrm{~m})$ over the southern part of the EM region through the seasons of winter, spring, summer and autumn as it is clear in Figures 4(a)-(d) respectively.

5) It is becoming clear that, there exist a positive anomaly in precipitation rate over only the northern part of the EM region in winter season. The anomaly of precipitation rate reached to $(+0.4 \mathrm{~mm})$ over Cyprus in winter, see Figure 5(a). It is reached to $(+0.5 \mathrm{~mm})$ over north of Greece and the eastern part of Turkey in spring season. Meanwhile, the southern part of the EM region has precipitation rate around its normal values, as it is clear in Figure 5(b).

NCEP/NCAR Reanalysis

500mb Geopotential Height (m) Composite Anomaly 1981-2010 climo

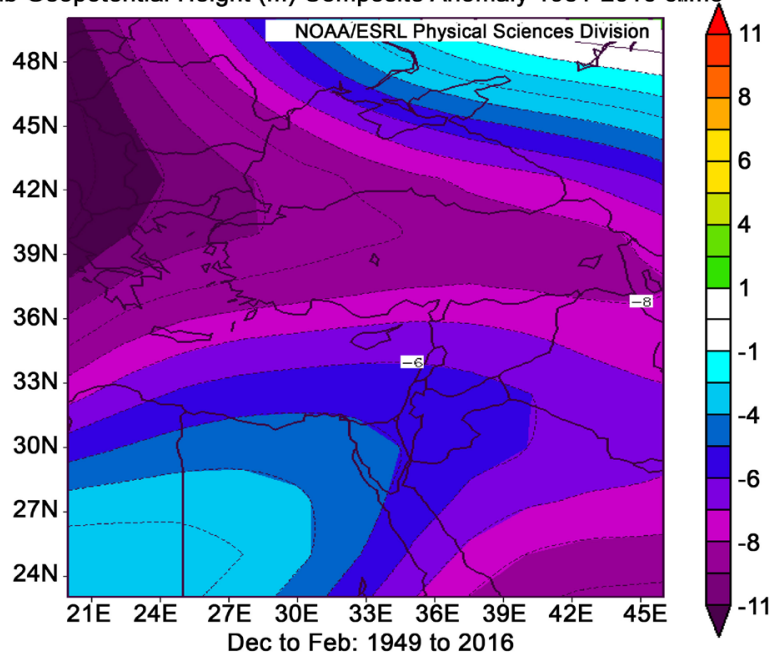

(a)

NCEP/NCAR Reanalysis

500mb Geopotential Height (m) Composite Anomaly 1981-2010 climo

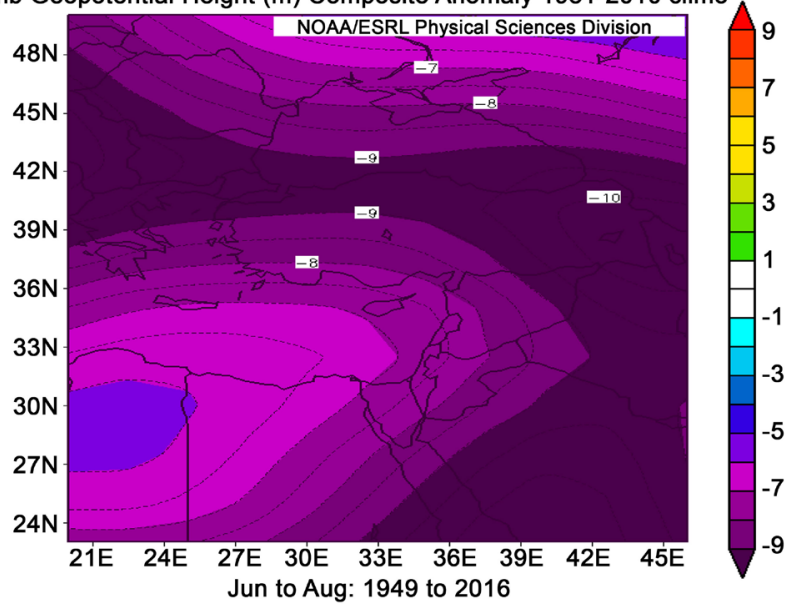

(c)
NCEP/NCAR Reanalysis

500mb Geopotential Height (m) Composite Anomaly 1981-2010 climo

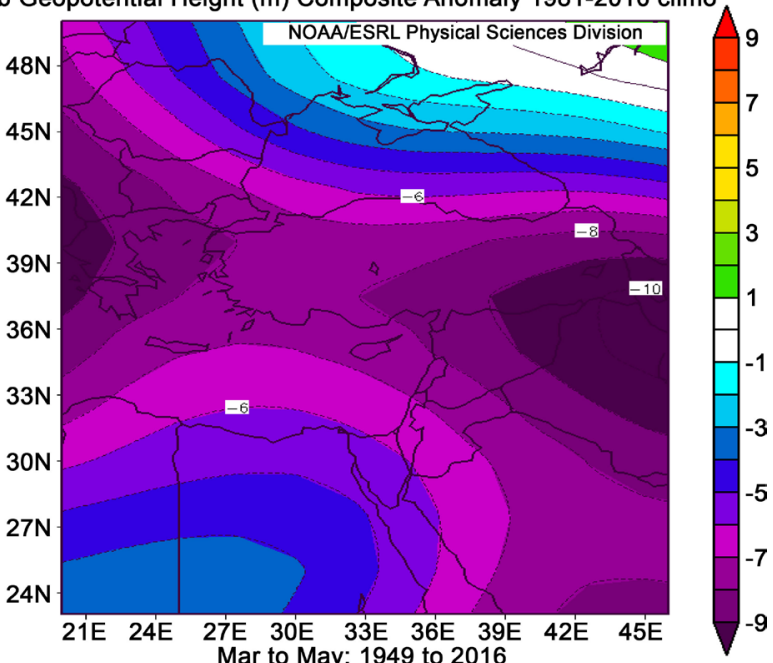

(b)

NCEP/NCAR Reanalysis

500mb Geopotential Height (m) Composite Anomaly 1981-2010 climo

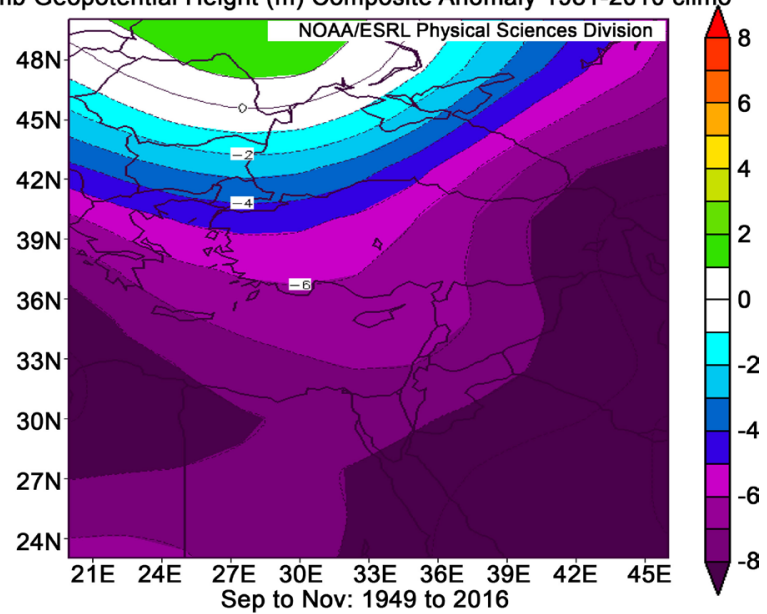

(d)

Figure 4. Seasonal distribution of the geopotential height anomaly at 500-hpa level over the Eastern Mediterranean region through the period (1949-2016). (a) For winter season, (b) For spring season, (c) For summer season, and (d) For autumn season. 


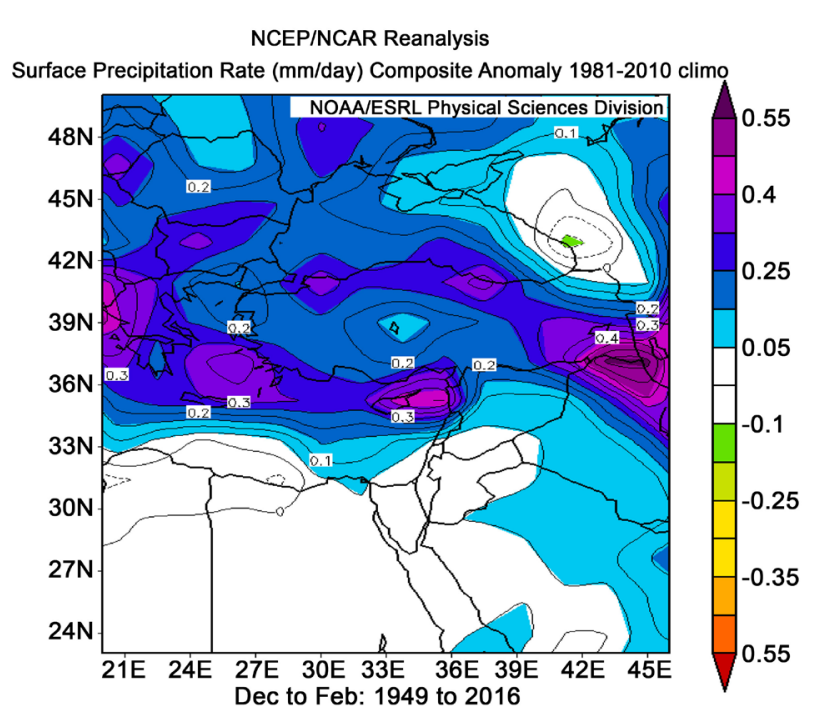

(a)

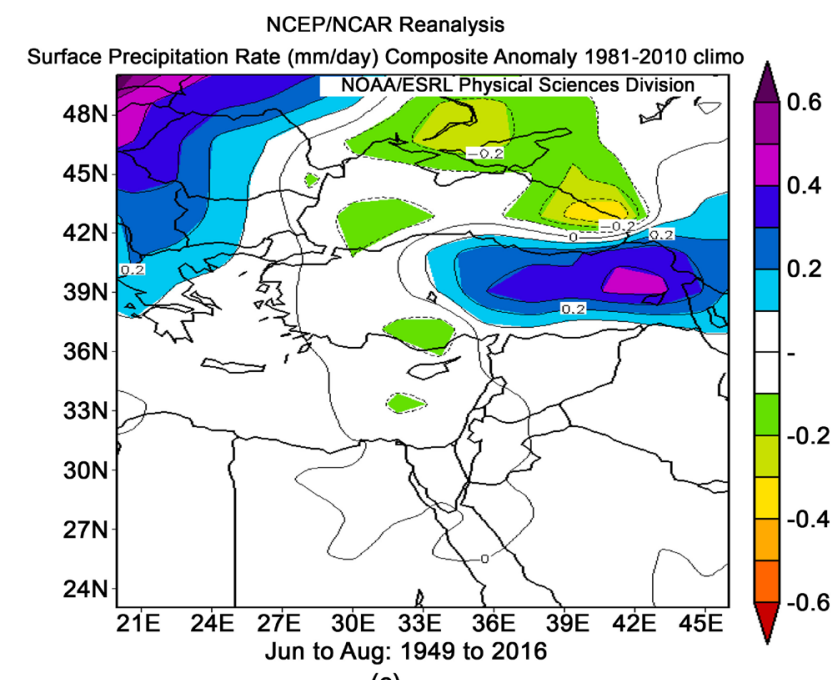

(c)

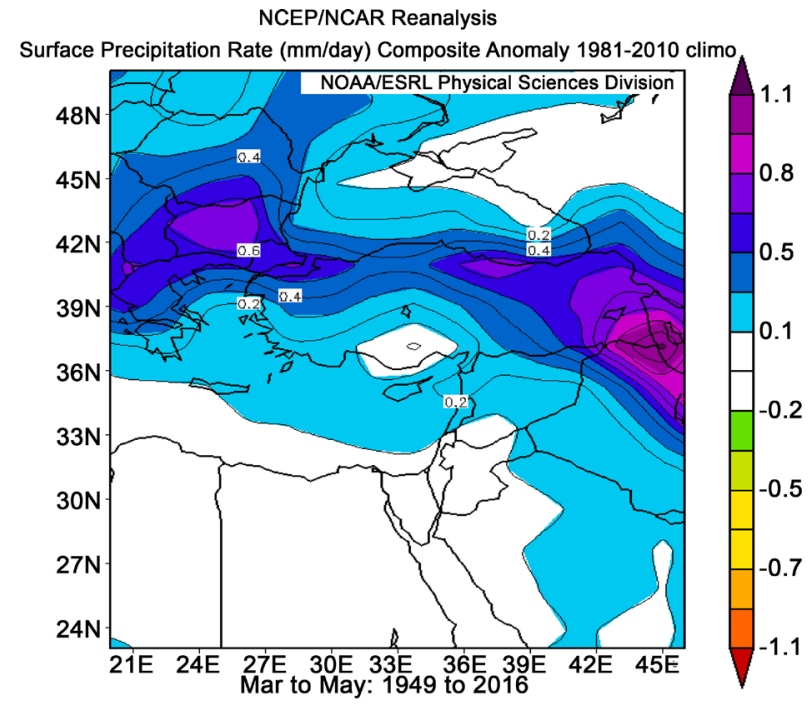

(b)

NCEP/NCAR Reanalysis

Surface Precipitation Rate (mm/day) Composite Anomaly 1981-2010 climo

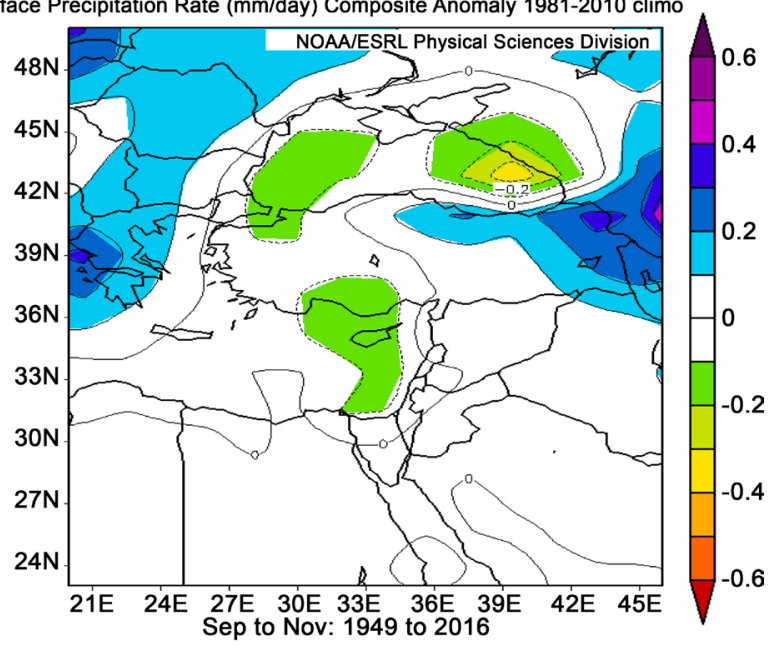

(d)

Figure 5. Seasonal distribution of precipitation rate ( $\mathrm{mm} /$ day) for the Eastern Mediterranean region through the period (19492016). (a) For winter season, (b) For spring season, (c) For summer season, and (d) For autumn season.

6) In summer season the precipitation rate is around its normal values except the eastern part of Turkey it is increasing rather than its normal with $(+0.4 \mathrm{~mm})$ as shown in Figure 5(c). Precipitation rate is around its normal values in autumn season. There are no significant anomaly values of precipitation rates for that season, as illustrates in Figure 5(d).

7) The seasonal time series analysis of $1000 \mathrm{hpa}$ level temperature over the EM region during the period (1949-2016) shows that for winter season the trend of it is a constant positive trend near the normal value. Meanwhile, for another season's temperature has an outstanding positive trend, Figure 6(a). The trend of temperature at $500 \mathrm{hpa}$ level is a positive trend as it is clear in Figure 6(b). The trend of mean sea level pressure is less than its normal values for the period (1949-2000). After that period, it is slightly more than the normal with a positive 


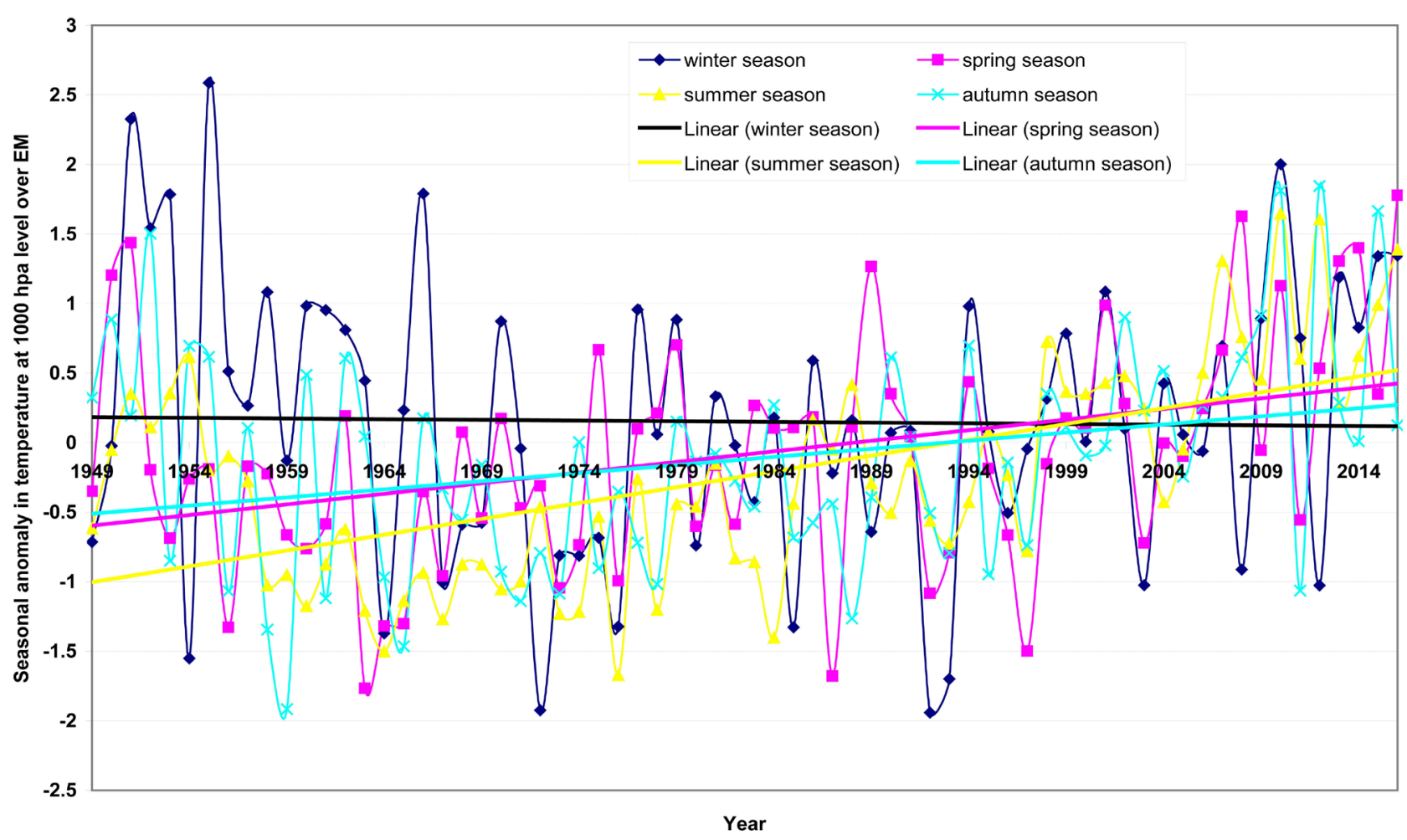

(a)

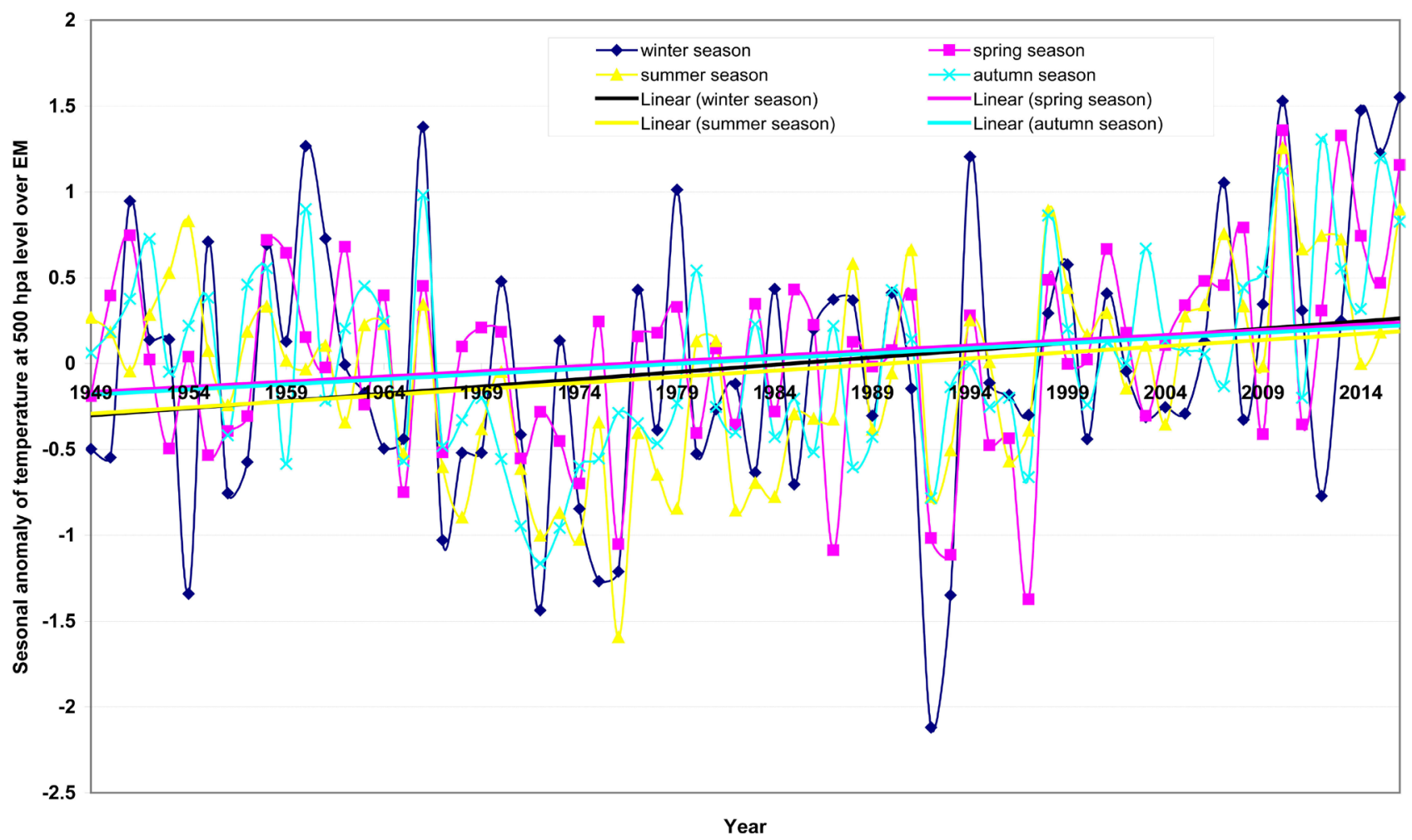

(b) 


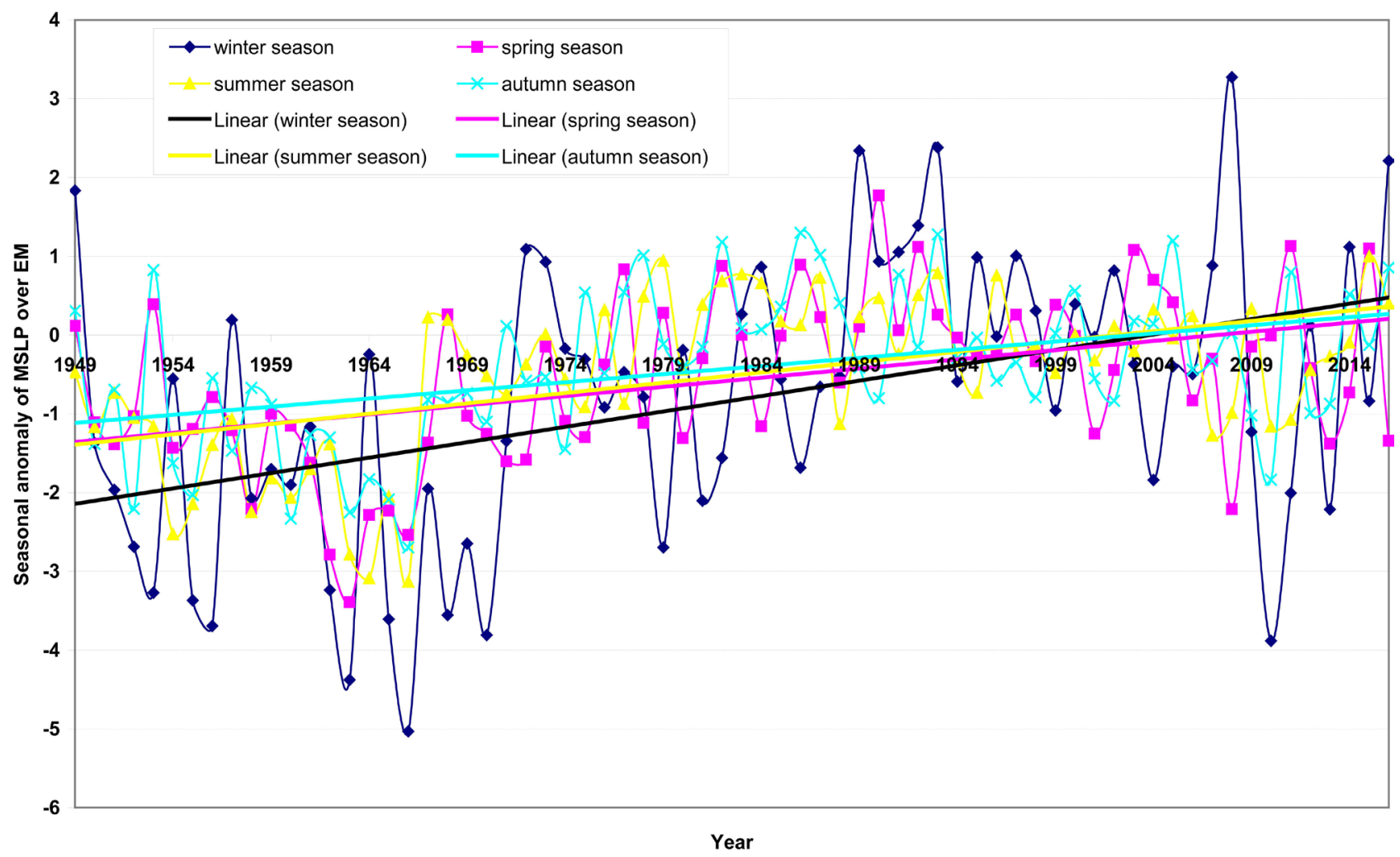

(c)

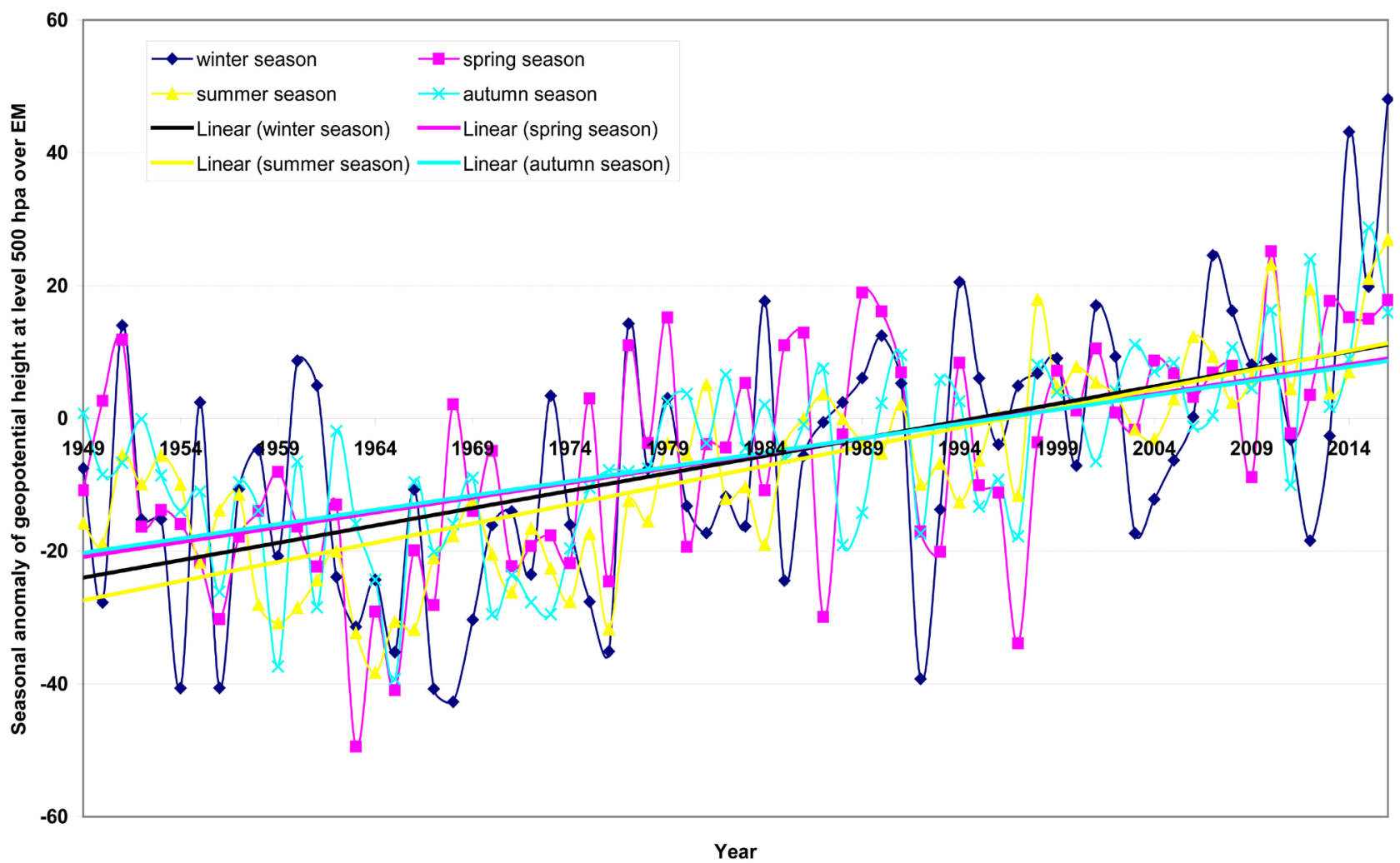

(d) 


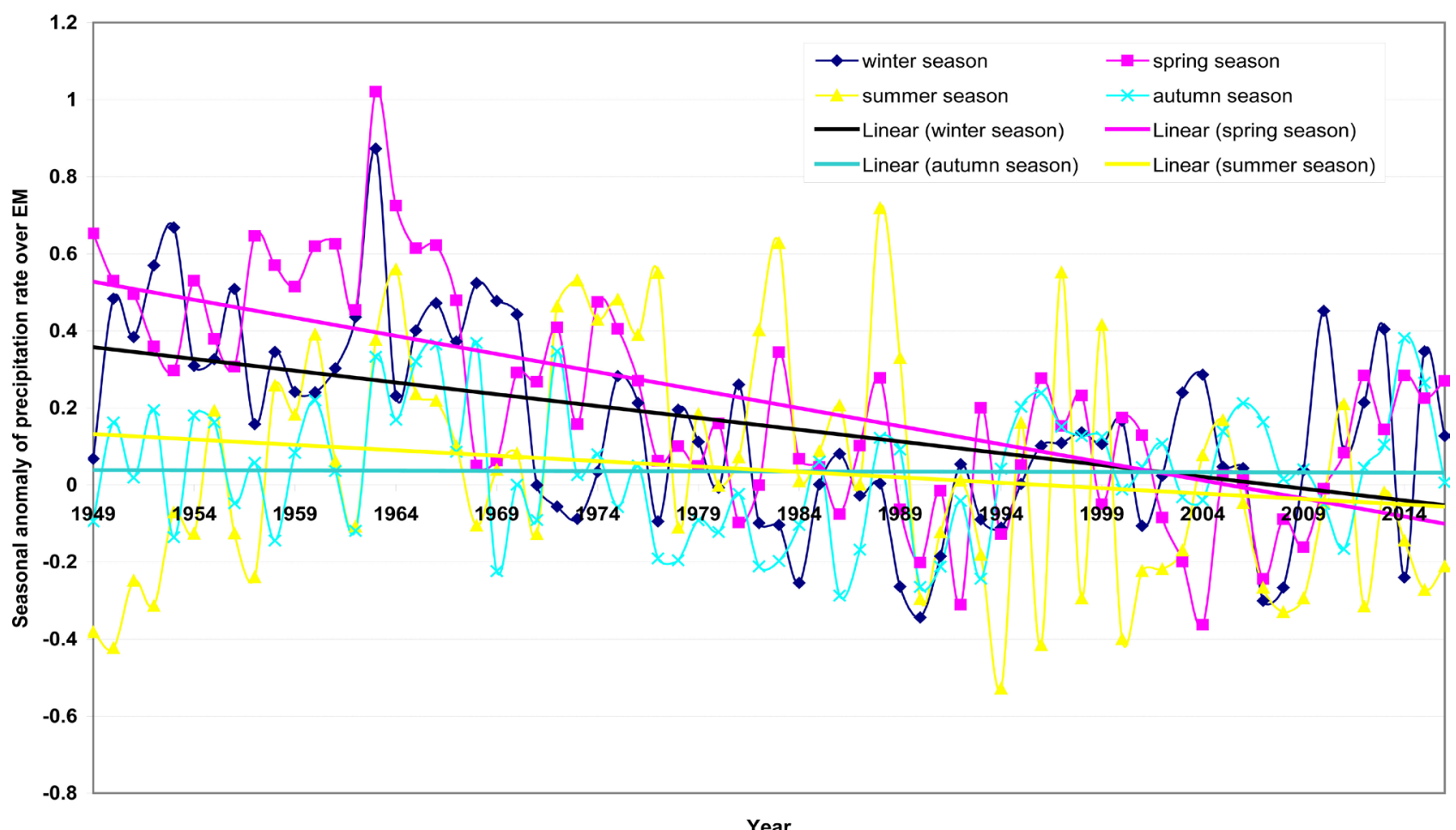

(e)

Figure 6. Time series of the seasonal anomaly of the climatic parameters over the Eastern Mediterranean region through the period (1949-2016). (a) Surface air temperature, (b) 500 hpa level air temperature, (c) Mean sea level pressure, (d) 500 hpa level geopotential height, (e) Precipitation rate.

trend through the period of study as it is clear in Figure 6(c). There is a sharply positive trend of geopotential height values at level $500 \mathrm{hpa}$ for all seasons over the EM region as illustrated in Figure 6(d). Time series analysis of seasonal precipitation rates over the EM region revealed that there is a negative trend of rainfall through the study period (1949-2016), as shown in Figure 6(e).

\subsection{The Interannual Climatic Variability over EM Region through the Period (1949-2016)}

For the study of interannual climatic variability over the EM region through the period (1949-2010), the monthly data of NCEP/NCAR reanalysis data for the meteorological parameters (air temperature at the surface, $1000 \mathrm{hpa}$ level, 500 hpa level, $500 \mathrm{hpa}$ geopotential height, mean sea level pressure and precipitation rate) are used. For the annual normal values of the meteorological elements, "annual climatic mean values "are taken for the period (1981-2010). Anomaly and time series methods for the above-mentioned meteorological elements are used. The results revealed that:

1) It is clear that the annual surface air temperature is less than its normal values and reached $\left(-0.3^{\circ} \mathrm{C}\right)$ less the normal value over almost of EM region. Meanwhile, it is has value more than its normal and reached to $\left(+0.3^{\circ} \mathrm{C}\right)$ over the eastern part of Turkey during the period (1949-2016), see Figure 7(a). 500 


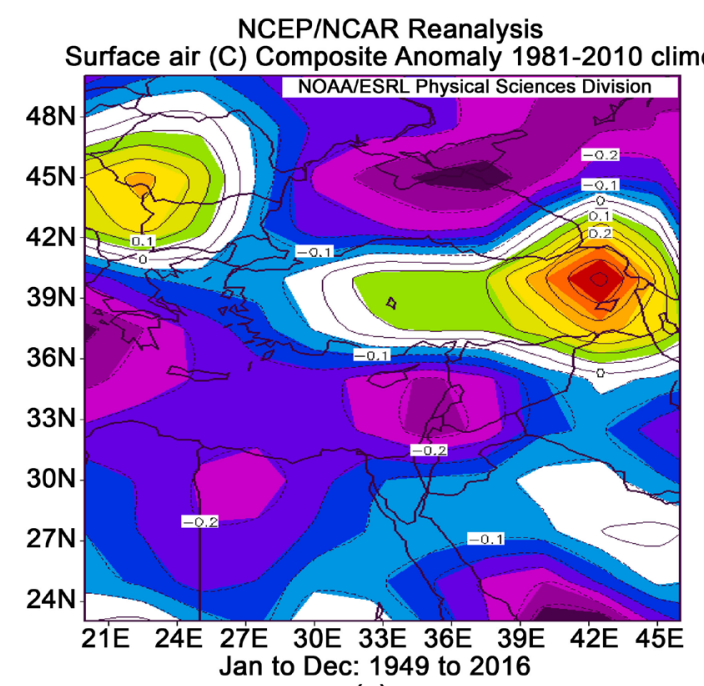

(a)

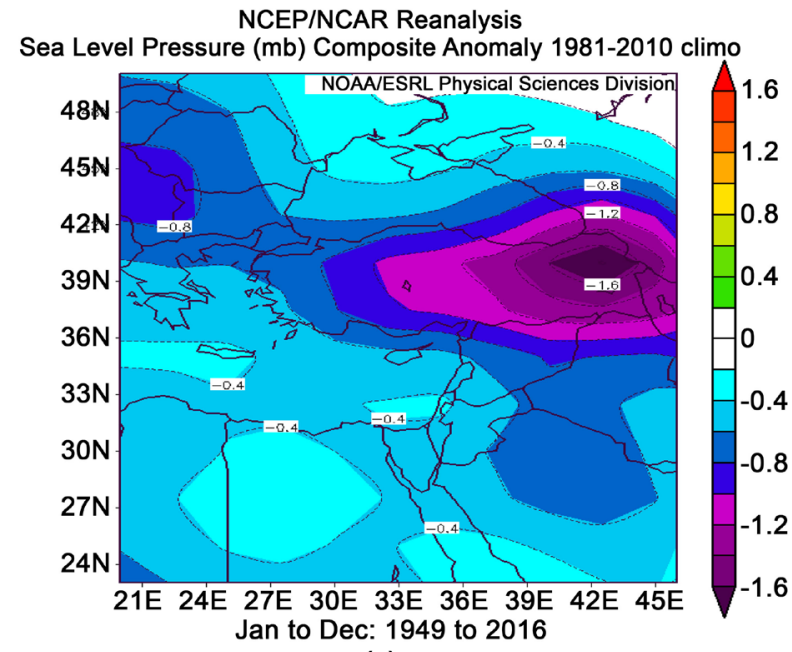

(c)

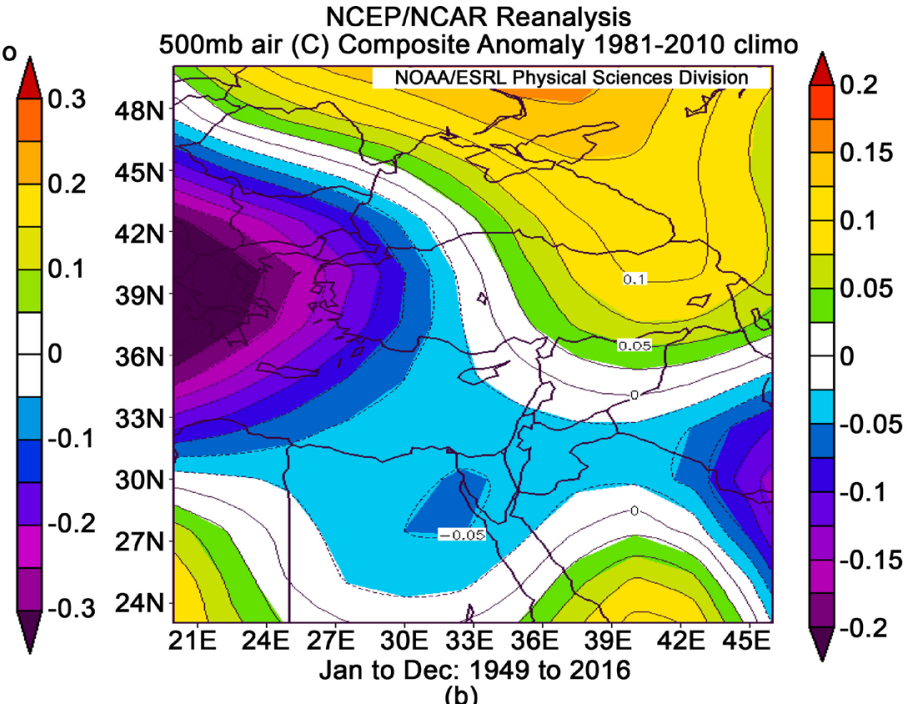

(b)

NCEP/NCAR Reanalysis

$500 \mathrm{mb}$ Geopotential Height (m) Composite Anomaly 1981-2010 climo

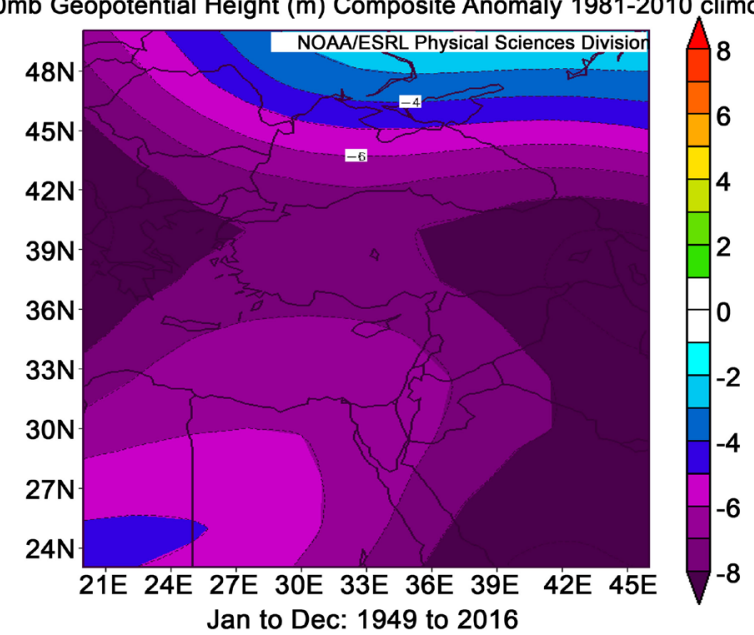

(d)

NCEP/NCAR Reanalysis

Surface Precipitotion Rate (mm/day) Composite Anomaly 1981-2010 climo

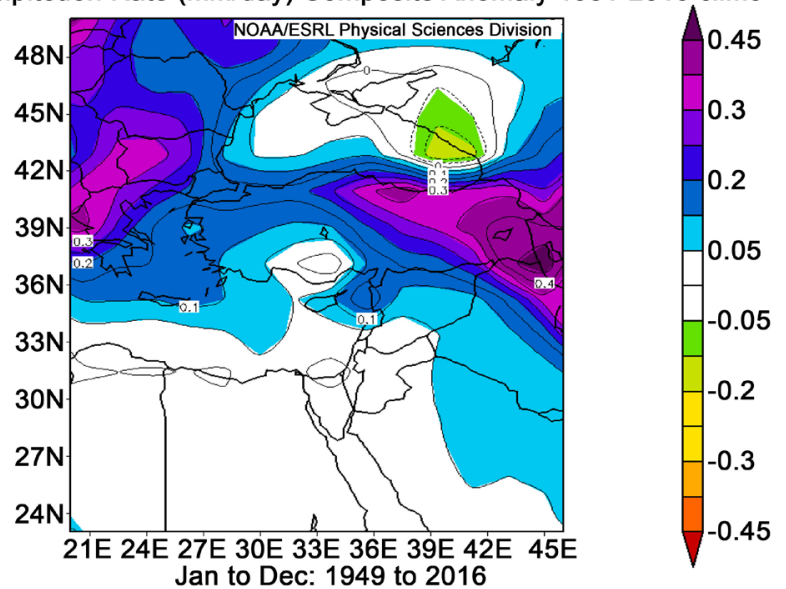

(e)

Figure 7. Anomaly of the annual distribution of the climatic parameters over the Eastern Mediterranean region through the period (1949-2016). (a) Surface air temperature, (b) 500 hpa level air temperature, (c) Mean sea level pressure, (d) 500 hpa level geopotential height, (e) Precipitation rate. 
hpa level temperature anomaly has a negative value and reached to $\left(-0.2^{\circ} \mathrm{C}\right)$ over Greece as shown in Figure 7(b). From analysis of sea level pressure, it has a value less than the normal values over the EM region and reached to (-1.6 hpa) over the eastern part of Turkey as illustrated in Figure 7(c). Geopotential height anomaly over $500 \mathrm{hpa}$ level has a negative value and reached to $(-8 \mathrm{~m})$ over western and eastern parts of the EM region as it is clear in Figure 7(d). In addition to that, there is a positive anomaly of annual rainfall amounts over the northern part of the EM region. Meanwhile, it has value near to normal value over the southern part of EM region (the north of Africa) through the period of study, see Figure 7(e).

2) Time series analysis of the annual temperature at $1000 \mathrm{hpa}$ level shows temperature varies from year to year with a positive trend over the EM region through the study period, as shown in Figure 8(a). The variability of temperature at $500 \mathrm{hpa}$ level is like to be in the same manner of temperature at $1000 \mathrm{hpa}$ level in general, see Figure 8(b). The annual variability of mean sea level pressure over EM has an outstanding variety through the period of study. Whereas, almost of the years has negative anomaly, but it has a sharply positive trend as illustrated in Figure 8(c). In general speaking the variability and trend of geopotential height at $500 \mathrm{hpa}$ level like the same manner of mean sea level pressure variability and trend as it became clear in Figure 8(d). The precipitation rate decreases with time and has a negative trend over the EM region through the study period as observed from Figure 8(e).

\subsection{Study of the Teleconnection between the Meteorological Elements over EM Region through the Period (1949-2016)}

To study the seasonal and annual teleconnection between the meteorological elements over the EM region the linear correlation coefficient techniques are used. The results observed that:

1) For the winter season, there is a strong direct relationship between the 500 hpa level air temperature and $1000 \mathrm{hpa}$ level air temperature with a correlation coefficient (0.818) over the EM region through the period of study. In addition to that, there is an outstanding direct relation of $500 \mathrm{hpa}$ level geopotential height and $1000 \mathrm{hpa}$ level air temperature with a correlation coefficient (0.760). Meanwhile, there exists an inverse relationship between the precipitation rate over the EM region and mean surface pressure with a correlation coefficient $(-0.784)$, as it is clear from Table 1 .

2) For the spring season, there is a strong direct relationship between the 1000 hpa level air temperature and $500 \mathrm{hpa}$ level geopotential height with a correlation coefficient (0.859) over the EM region. In addition, there is an outstanding direct relation of $1000 \mathrm{hpa}$ level air temperature and $500 \mathrm{hpa}$ level geopotential height with a correlation coefficient (0.749), as shown in Table 2.

3) For the summer season, there is a strong direct relationship between the $1000 \mathrm{hpa}$ level air temperature and $500 \mathrm{hpa}$ level geopotential height with a cor- 


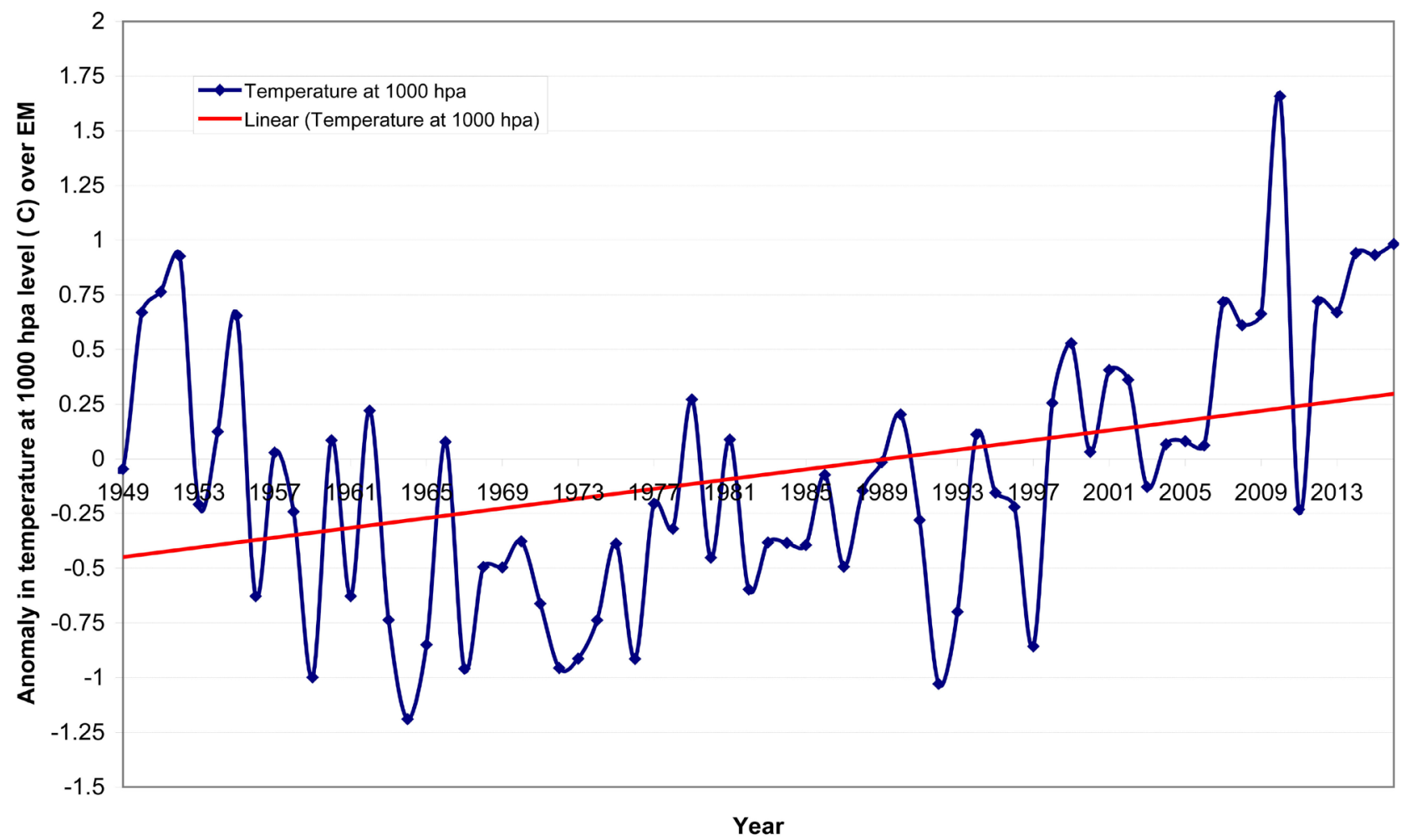

(a)

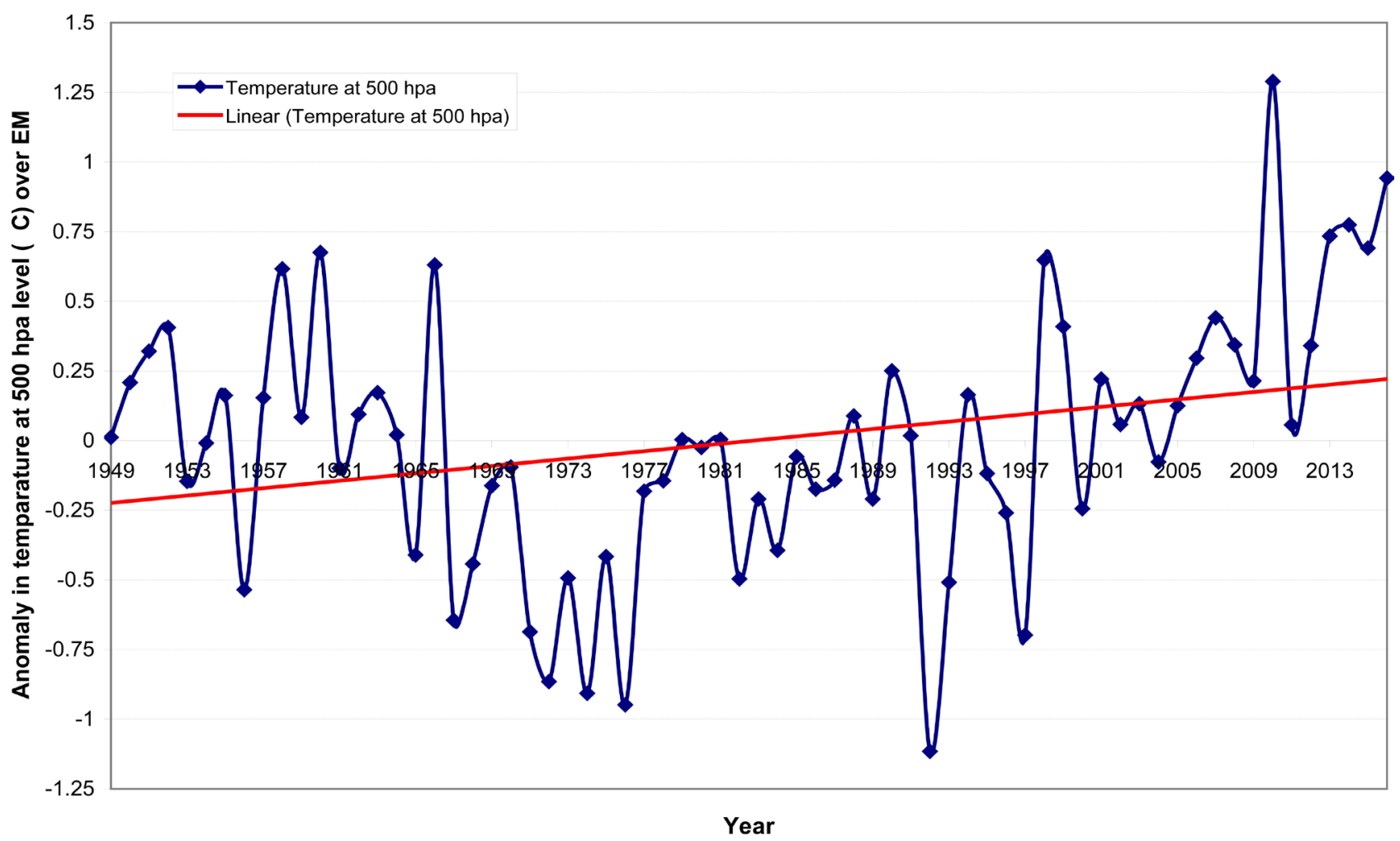

(b) 


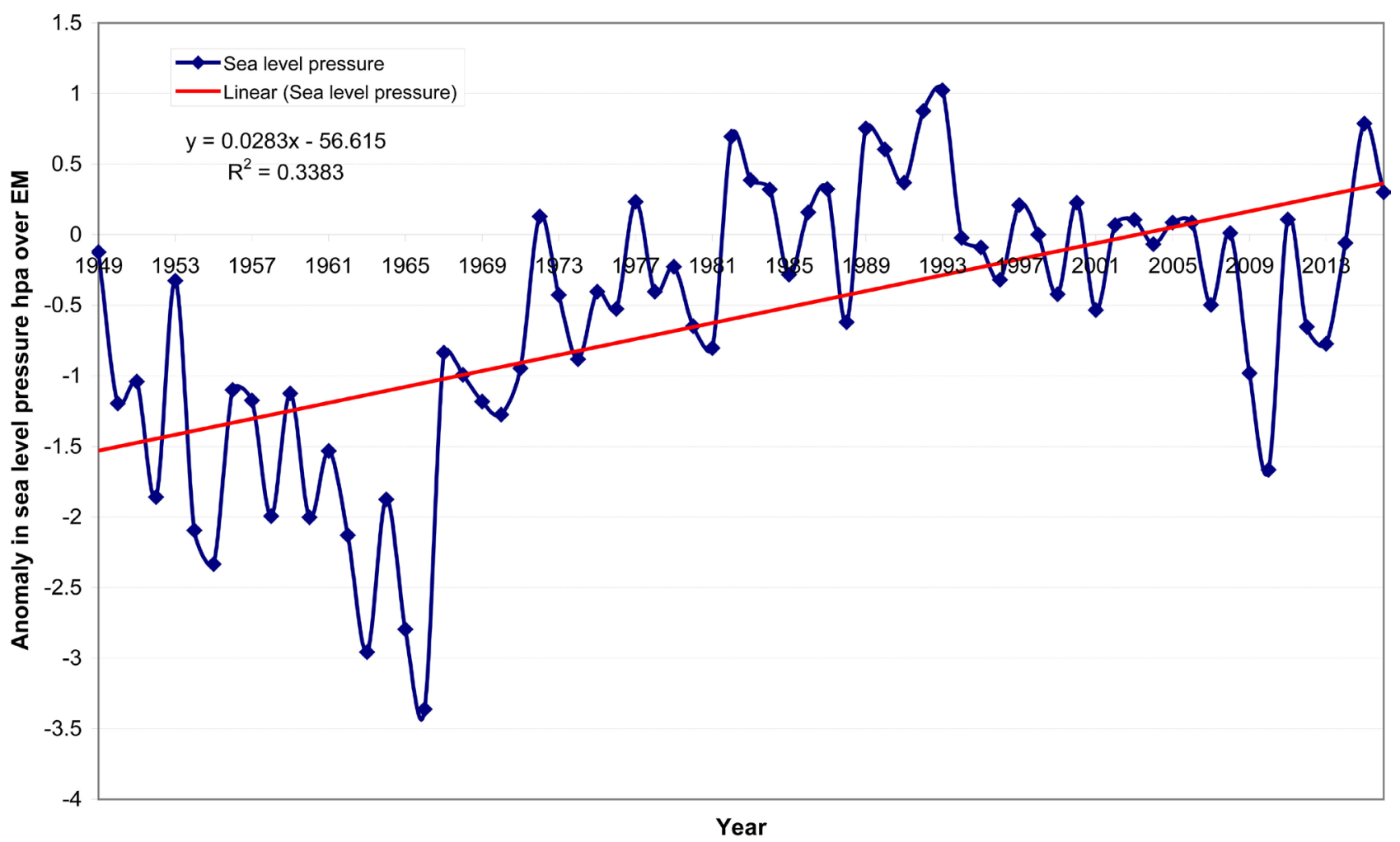

(c)

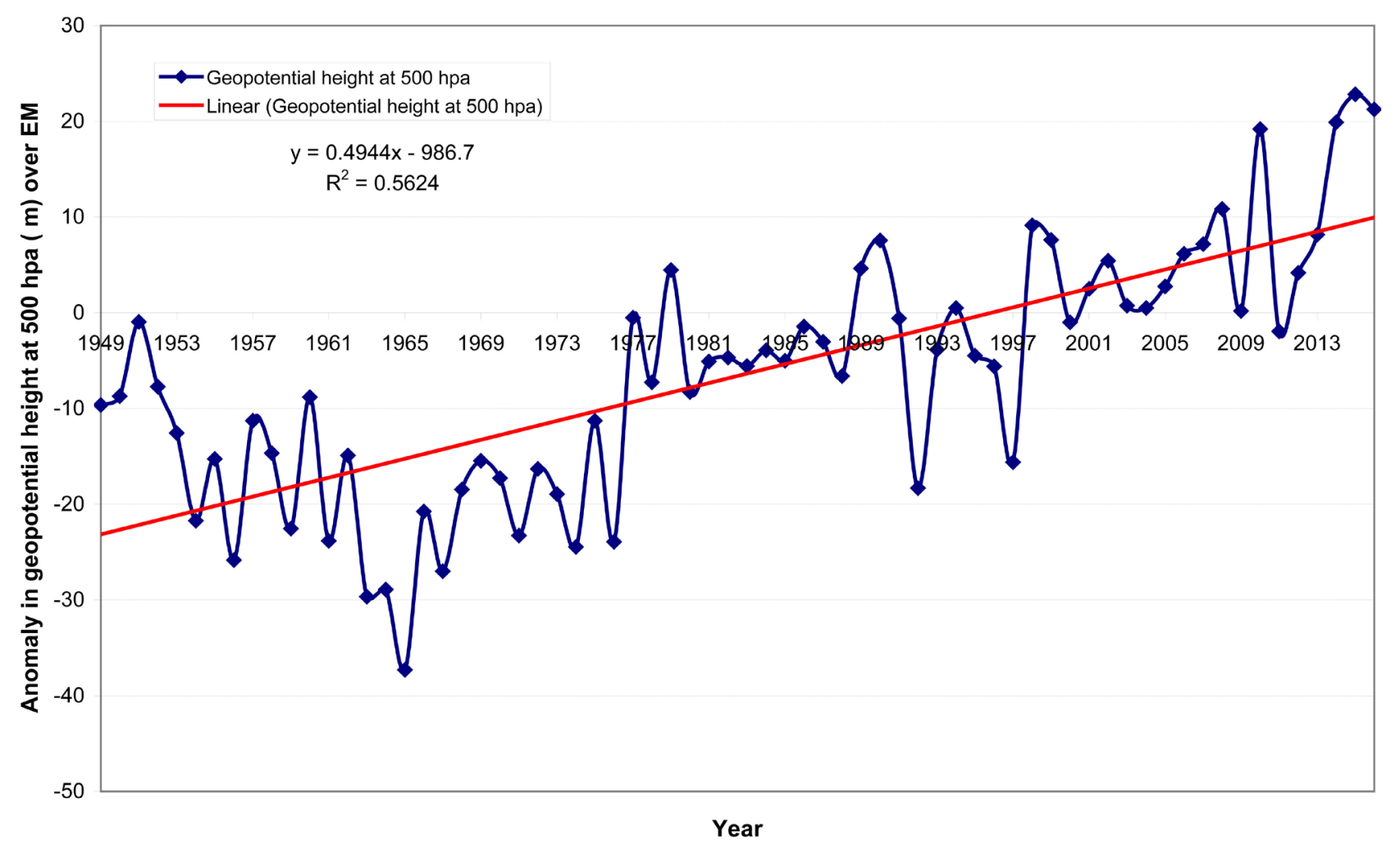

(d) 


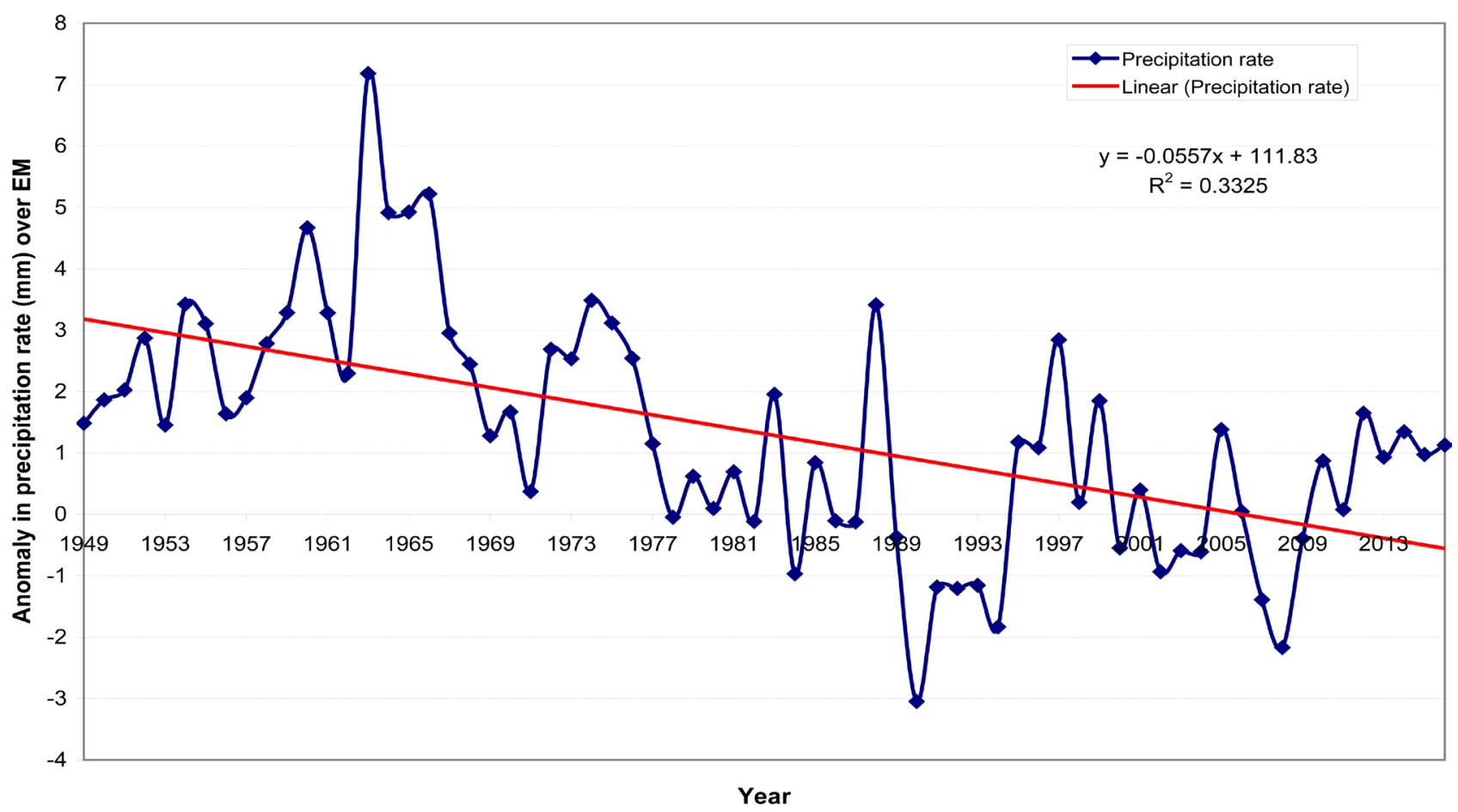

(e)

Figure 8. Time series of the annual anomaly of the climatic parameters over the Eastern Mediterranean region through the period (1949-2016). (a) Surface air temperature, (b) 500 hpa level air temperature, (c) Mean sea level pressure, (d) 500 hpa level geopotential height, (e) Precipitation rate.

Table 1. Winter season correlation coefficient matrix between the meteorological elements over the Eastern Mediterranean region through the period (1948-2016).

\begin{tabular}{ccccccc}
\hline Meteorological elements and its Correl. Coef. & B & C & D & E & F \\
\hline B & 1 & 0.818 & -0.505 & 0.505 & 0.304 \\
C & 0.818 & 1 & -0.232 & 0.760 & -0.019 \\
D & -0.505 & -0.232 & 1 & 0.408 & -0.784 \\
E & 0.505 & 0.760 & 0.408 & 1 & -0.525 \\
F & 0.304 & -0.019 & -0.784 & -0.525 & 1
\end{tabular}

Whereas, B: The mean air temperature over the EM at 1000 hpa level; C: The mean air temperature over the EM at 500 hpa level; D: The mean sea level pressure on the EM; E: The mean geopotential height over the EM at 500 hpa level; F: The precipitation rate of the EM.

Table 2. Spring season correlation coefficient matrix between the meteorological elements over the Eastern Mediterranean region through the period (1948-2016).

\begin{tabular}{cccccc}
\hline Meteorological elements and its Correl. Coef. & B & C & D & E & F \\
\hline B & 1 & 0.749 & 0.018 & 0.856 & -0.281 \\
C & 0.749 & 1 & -0.218 & 0.688 & -0.007 \\
D & 0.018 & -0.218 & 1 & 0.448 & -0.693 \\
E & 0.856 & 0.688 & 0.448 & 1 & -0.552 \\
F & -0.281 & -0.007 & -0.693 & -0.552 & 1 \\
\hline
\end{tabular}


relation coefficient $(0.881)$ over the EM region as illustrated in Table 3.

4) For autumn season, there is an outstanding direct relationship between the 500 hpa level air temperature and 1000 hpa level air temperature with a correlation coefficient (0.709) over the EM region. In addition, there is an outstanding direct relation of $1000 \mathrm{hpa}$ level air temperature and $500 \mathrm{hpa}$ level geopotential height with a correlation coefficient (0.725), as clear from Table 4.

5) For annual correlations, there is a strong direct annual relationship between the 500 hpa level air temperature and 1000 hpa level air temperature with a correlation coefficient (0.800) over the EM region through the period of study. In addition to that, there is an outstanding direct relation of 1000 hpa level air temperature and $500 \mathrm{hpa}$ level geopotential height with a correlation coefficient (0.759). Meanwhile, there exists an inverse relationship between the annual precipitation rate over the EM region and mean surface pressure with a correlation coefficient (-0.744), as it is clear from Table 5.

\section{Discussion and Conclusion}

The seasonal and interannual climatic variability over the EM region through the period (1949-2016) was investigated. To challenge this aim, the monthly data of NCEP/NCAR reanalysis data for the meteorological parameters (air temperature at the surface, $1000 \mathrm{hpa}$ level, $500 \mathrm{hpa}$ level, 500 hpa geopotential height, mean sea level pressure and precipitation rate) have been used. It is

Table 3. Summer season correlation coefficient matrix between the meteorological elements over the Eastern Mediterranean region through the period (1948-2016).

\begin{tabular}{cccccc}
\hline $\begin{array}{c}\text { Meteorological elements } \\
\text { and its Correl. Coef. }\end{array}$ & B & C & D & E & F \\
\hline B & 1 & 0.697 & 0.106 & 0.881 & -0.462 \\
C & 0.697 & 1 & -0.394 & 0.511 & -0.348 \\
D & 0.106 & -0.394 & 1 & 0.495 & -0.203 \\
E & 0.881 & 0.511 & 0.495 & 1 & -0.436 \\
F & -0.462 & -0.348 & -0.203 & -0.436 & 1 \\
\hline
\end{tabular}

Table 4. Autumn season correlation coefficient matrix between the meteorological elements over the Eastern Mediterranean region through the period (1948-2016).

\begin{tabular}{cccccc}
\hline $\begin{array}{c}\text { Meteorological elements } \\
\text { and its Correl. Coef. }\end{array}$ & B & C & D & E & F \\
\hline B & 1 & 0.709 & -0.299 & 0.725 & 0.145 \\
C & 0.709 & 1 & -0.314 & 0.666 & 0.128 \\
D & -0.299 & -0.314 & 1 & 0.340 & -0.544 \\
E & 0.725 & 0.666 & 0.340 & 1 & -0.210 \\
F & 0.145 & 0.128 & -0.544 & -0.210 & 1 \\
\hline
\end{tabular}


Table 5. Annual correlation coefficient matrix between the meteorological elements over the Eastern Mediterranean region through the period (1948-2016).

\begin{tabular}{cccccc}
\hline $\begin{array}{c}\text { Meteorological elements } \\
\text { and its Correl. Coef. }\end{array}$ & B & C & D & E & F \\
\hline B & 1 & 0.800 & -0.024 & 0.759 & -0.261 \\
C & 0.800 & 1 & -0.243 & 0.620 & -0.009 \\
D & -0.024 & -0.243 & 1 & 0.549 & -0.744 \\
E & 0.759 & 0.620 & 0.549 & 1 & -0.620 \\
F & -0.261 & -0.009 & -0.744 & -0.620 & 1 \\
\hline
\end{tabular}

found that the climatic variability distribution of surface air temperature, 500 hpa level temperature varied; 500 hpa geopotential height, means surface pressure, and precipitation rate varied from season to season and from region to region through the study period. This sharp variety of climatic parameters from season to season results from the change of the originality of air currents over the EM from season to season. There is a seasonal positive trend of temperature at $1000 \mathrm{hpa}$ and $500 \mathrm{hpa}$ and geopotential height of $500 \mathrm{hpa}$ level over the EM region through the period of study. Meanwhile, it found a seasonal negative trend of mean sea level pressure and precipitation rate over EM region during the study period (1949-2016). From analysis of interannual distribution of climatic variations over EM region, it noticed that almost of meteorological elements had values less than its normal. However, the rainfall amount, distribution have an outstanding positive anomaly over the northern part of EM region. Annual time series analysis shows that there is a positive trend of annual air temperature at the levels of $1000 \mathrm{hpa}$ and $500 \mathrm{hpa}$. Meanwhile, there exists an annual negative trend anomaly of mean sea level pressure, 500 hpa geopotential height and precipitation rate over the EM region through the study period. A teleconnection study of climatic variability of the meteorological elements over the EM region through the period (1949-2016) is done. For the winter season, there is a strong direct relationship between the 500 hpa level air temperature and $1000 \mathrm{hpa}$ level air temperature. In addition to that, there is an outstanding direct relation of $500 \mathrm{hpa}$ level geopotential height and $1000 \mathrm{hpa}$ level air temperature. Meanwhile, there exists an inverse relationship between the precipitation rate over the EM region and mean surface pressure with correlation coefficient. For the spring season, there is a strong direct relationship between the $1000 \mathrm{hpa}$ level air temperature and $500 \mathrm{hpa}$ level geopotential height. Moreover, there is an outstanding direct relation of $1000 \mathrm{hpa}$ level air temperature and $500 \mathrm{hpa}$ level geopotential height. For the summer season, there is a strong direct relationship between the $1000 \mathrm{hpa}$ level air temperature and $500 \mathrm{hpa}$ level geopotential height. For autumn season, there is an outstanding direct relationship between the $500 \mathrm{hpa}$ level air temperature and $1000 \mathrm{hpa}$ level air temperature. In addition, there is an outstanding direct relation of $1000 \mathrm{hpa}$ level air temperature and 
$500 \mathrm{hpa}$ level geopotential height. For annual correlations, there is a strong direct annual relationship between the $500 \mathrm{hpa}$ level air temperature and $1000 \mathrm{hpa}$ level air temperature through the period of study. In addition to that, there is an outstanding annual direct relation of $1000 \mathrm{hpa}$ level air temperature and $500 \mathrm{hpa}$ level geopotential height. Meanwhile, there exists an inverse relationship between the annual precipitation rate over the EM region and mean surface pressure. So the climatic regime over the EM region is a complex regime. The results of this scientific work are the point strength for a future research of the climatic variability and development of climatic features over the EM region. Finally, one can conclude that there exists a seasonal and interannual dramatic climatic variability over the EM region through the period (1949-2016).

\section{Acknowledgements}

The author hopes to thank the NOAA/ESRL Physical Sciences Division. Image provided by the NOAA/ESRL Physical Sciences Division, Boulder Colorado from their Web site at http://www.esrl.noaa.gov/psd/.

\section{References}

[1] MedCLIVAR (2007) Mediterranean Climate Variability. Report for the CLIVAR SSG15, Geneva.

[2] Segal, M., Shafir, H., Mandel, M., Alpert, P. and Balmor, Y. (1992) Climatic-Related Evaluations of the Summer PeakHours' Electric Load in Israel. Journal of Applied Meteorology, 31, 1492-1498. https://doi.org/10.1175/1520-0450(1992)031<1492:CREOTS >2.0.CO;2

[3] Bolle, H.-J. (2003) Climate, Climate Variability, and Impacts in the Mediterranean Area: An Overview. In: Bolle, H.-J., Ed., Mediterranean Climate-Variability and Trends, Springer, Berlin, 5-86. https://doi.org/10.1007/978-3-642-55657-9_2

[4] Lionello, et al. (2006) The Mediterranean Climate: An Overview of the Main Characteristics and Issues. Developments in Earth \& Environmental Sciences, 4, 1-26. https://doi.org/10.1016/S1571-9197(06)80003-0

[5] Flocas, A.E. and Hatzaki, M. (2009) Climatic Variability in Eastern Mediterranean: Dynamic Mechanisms and Impact on Regional Climate. 5 th International Conference on Energy, Environment, Ecosystems and Sustainable Development, Vouliagmeni, 28-30 September 2009, 113-115.

[6] Issar, A.S. and Zohar, M. (2007) Climate Change, Environment and Civilization in the Middle East. Springer, Berlin.

[7] Krichak, S.O., Tsidulko, M. and Alpert, P. (2000) Monthly Synoptic Patterns with Wet/Dry Conditions in the Eastern Mediterranean. Theoretical and Applied Climatology, 65, 215-229. https://doi.org/10.1007/s007040070045

[8] Barth, H.-J. and Steinkohl, F. (2004) Origin of Winter Precipitation in the Central Coastal Lowlands of Saudi Arabia. Journal of Arid Environments, 57, 101-115. https://doi.org/10.1016/S0140-1963(03)00091-0

[9] Evans, J.P., Smith, R.B. and Oglesby, R.J. (2004) Middle East Climate Simulation and Dominant Precipitation Processes. International Journal of Climatology, 24, 1671-1694. https://doi.org/10.1002/joc. 1084 
[10] Önol, B. and Semazzi, F.H.M. (2009) Regionalization of Climate Change Simulations over the Eastern Mediterranean. Journal of Climate, 22, 1944-1961. https://doi.org/10.1175/2008JCLI1807.1

[11] Evans, J.P. (2010) Global Warming Impact on the Dominant Precipitation Processes in the Middle East. Theoretical and Applied Climatology, 99, 389-402. https://doi.org/10.1007/s00704-009-0151-8

[12] Lelieveld, J., Hadjinicolaou, P., Kostopoulou, E., Chenoweth, J., El Maayar, M., Giannakopoulos, C., Hannides, C., Lange, M.A., Tanarhte, M., Tyrlis, E. and Xoplaki, E. (2012) Climate Change and Impacts in the Eastern Mediterranean and the Middle East. Climate Change, 114, 667-687. https://doi.org/10.1007/s10584-012-0418-4

[13] Hafez, Y.Y. (2007) The Connection between the 500 HPA Geopotential Height Anomalies over Europe and the Abnormal Weather in Eastern Mediterranean during Winter 2006. International Journal of Meteorology, 32, 335-348.

[14] Hafez, Y.Y. (2008) The Teleconnection between the Global Mean Surface Air Temperature and Precipitation over Europe. International Journal of Meteorology, 33, 230-236.

[15] Shohami, D., Dayan, U. and Morin, E. (2011) Warming and Drying of the Eastern Mediterranean: Additional Evidence from Trend Analysis. Journal of Geophysical Research, 116, D22101. https://doi.org/10.1029/2011JD016004

[16] Hafez, Y.Y. and Almazroui, M. (2016) Study of the Relationship between Geopotential Height Anomaly over Europe and Extreme Abnormal Weather over the Eastern Mediterranean and Middle East during December 2013. Arabian Journal of Geosciences, 9, 409.

[17] Kalnay, E., Kanamitsu, M., Kistler, R., Collins, W., Deaven, D., Gandin, L., et al. (1996) The NCEP/NCAR 40 Year Reanalysis Project. Bulletin of the American Meteorological Society, 77, 437-471. https://doi.org/10.1175/1520-0477(1996)077<0437:TNYRP>2.0.CO;2

[18] Kendall, M.G. and Stuart, A. (1973) The Advanced Theory of Statistics. Volume 2, Inference and Relationship, Griffin. 